\title{
Extensive Proof-of-Concept Studies in TNF-Alpha Antagonists might be Responsible for A Delay of Patient Access in Pediatric Rheumatology
}

\author{
Nalân Utku1 ${ }^{1}$ Peter Schlattmann², Glyn Steventon ${ }^{3}$, Birka Lehmann ${ }^{4}$ and Jürgen Brunner ${ }^{5 *}$ \\ ${ }^{1}$ Institute of Medical Immunology, Charité, Berlin, Germany \\ ${ }^{2}$ Department of Medical Statistics, Informatics and Documentation, Jena University Hospital, Jena, Germany \\ ${ }^{3}$ Department of Pharmacology, Kings College, London, UK \\ ${ }^{4}$ Federal Institute for Drugs and Medical Devices, Germany \\ ${ }^{5}$ Department of Pediatrics, Medical University Innsbruck, Austria
}

*Corresponding author: Juergen Brunner, Department of Pediatrics, Medical University Innsbruck, Anichstrasse 35, 6020

Innsbruck, Austria

\section{ARTICLE INFO}

Received: 輩 September 21, 2021

Published: 慧 September 28, 2021

Citation: Nalân Utku, Peter Schlattmann, Glyn Steventon, Birka Lehmann, Jürgen Brunner. Extensive Proof-of-Concept Studies in TNF-Alpha Antagonists might be Responsible for A Delay of Patient Access in Pediatric Rheumatology. Biomed J Sci \& Tech Res 39(1)-2021. BJSTR. MS.ID.006244.

Keyword: Pediatrics; Trials; Approval

\section{ABSTRACT}

Background: Many medicinal products have been given to children without regulatory approval. The European and US regulatory authorities introduced legislation to improve the route to market for therapeutics for use in children in 2007. Thus, new drugs have to be clinically tested in children to gain approval in adults, unless predicted to be unsafe, ineffective or not needed in children.

Main body: Our meta-analysis focuses on the use of immune-modulatory biologics. It compares data obtained from studies using etanercept, infliximab and adalimumab in juvenile idiopathic arthritis (JIA) and adult rheumatoid arthritis (RA) and argues that efficacy and safety in children could be extrapolated from the data in a corresponding adult disease, although, for chimeric or pegylated biologics, PK/PD parameter analysis would need to be investigated before selecting the effective dose in children.

Conclusion: Use of this model has potential to enhance the clinical use of pediatric drugs, tailored to age, weight, and physiological development.

\section{Key Messages:}

a) Supplementary and extensive pediatric trials delay marketing approval for effective medicines for children

b) Adult trial results in RA together with PK studies in children are likely to be sufficient for marketing approval of TNF- $\alpha$ inhibitors for JIA

\section{Introduction}

In order to improve the route to market for approved pediatric therapeutics, the current Pediatric Regulation in the EU and the Food and Drug Administration (FDA) Amendments Act (FDAAA) were both adopted in 2007. These include incentives for the pharmaceutical industry to perform pediatric clinical studies, for example granting an extended patent protection time or marketing exclusivity for orphan medicinal products for a limited period. Between 2007 and 2013, the European Medicines Agency (EMA) and its Pediatric Committee assessed more than 600 pediatric investigation plans (PIPs) with an aim to provide data on the 
efficacy and safety of medicines for diseases of children. After almost a decade of experience of PIPs, it seemed important to evaluate the usability of data derived from clinical trials for new medicinal products in children for marketing authorization. This is particularly important in order to understand the need for, and extent of, clinical studies for new drugs in children in the future. The aim of this study is to evaluate whether proof-of-concept clinical trials need to be carried out at the existing rate and frequency, and whether data to support the use of new drugs in children can be extrapolated from adult trials of equivalent indications with focus on rheumatology. This evaluation should help to outline new guidance for clinical trials for new drugs in children to prevent unnecessary extensive trials of 'me-too' drugs.

\section{Strategy}

The review compared the effects of immune-modulatory drugs in adults and children, selected using the following criteria:

a) Biologics in the same class to treat arthritis

b) Clinically tested for the same or a similar indication in children and adults

c) Subject to a PIP in children and approved for use in adults.

Drugs selected for this review are biologics targeting TNF- $\alpha$ including adalimumab, etanercept, golimumab, and infliximab.

\section{TNF- $\alpha$ Inhibitors Tested in Adults and Children}

Etanercept (Enbrel, Pfizer) is a soluble decoy receptor for TNF. It was the first TNF- $\alpha$ inhibitor launched for treatment of RA. The drug was FDA-approved in November 1998, and by the EMA in February 2000. It is approved for the treatment of RA, JIA, psoriatic arthritis, plaque psoriasis and ankylosing spondylitis [1] as the first biologic to treat JIA. Adalimumab (Humira, Abbot [now: AbbVie]) is a monoclonal anti-TNF- $\alpha$ inhibitor. It was the first fully human IgG1 protein to be approved by the FDA in December 2002. It was approved by the EMA in September 2003. Adalimumab is indicated for the treatment of RA, JIA, psoriatic arthritis, ankylosing spondylitis, Crohn's disease, psoriasis and ulcerative colitis [2]. It was approved for JIA in 2008. Golimumab (Simponi, Janssen Biotech) is a human anti-TNFa IgG1א monoclonal antibody. Golimumab was approved in US and Canada as a treatment for RA, psoriatic arthritis, and spondylitis, and is undergoing regulatory review in the EU [3] for these indications. Golimumab missed the primary endpoint in JIA. Infliximab (Remicade, Janssen Biotech) is a chimeric monoclonal antibody directed against TNF- $\alpha$ which induces apoptosis in TNF- $\alpha$-receptor + cells. Infliximab is only approved for RA. It failed to meet primary endpoint in JIA and therefore has not been approved by the FDA in children for JIA. A waiver for the PIP was agreed in the EU. Infliximab is used off label in JIA as it has not been approved for this indication.

\section{Search Strategy}

The search was focused on RA in adults and on JIA, prescribing information, clinical trials websites and the FDA and EMA websites in order to identify relevant study information [4-16]. Keywords employed for the searches: Adalimumab, etanercept, golimumab, infliximab; juvenile idiopathic arthritis, JIA, juvenile rheumatoid arthritis, JRA, systemic juvenile idiopathic arthritis, SJIA, polyarticular juvenile idiopathic arthritis, PJIA; pediatrics, children, adults; tumor necrosis factor inhibitors, TNF- $\alpha$, phase III.

\section{Statistical Meta-Analysis}

Statistical analysis was performed using a logistic regression with random effects. The primary outcomes are the ACR50 and ACR70. The dependent variable is the number of patients who reach ACR50 or ACR70 based on the total number of patients treated. Independent variables are treatment, age group (children vs. adults) and time. Treatment is a categorical variable, which compares several treatment regimens with placebo. As not every study has a placebo control arm, we therefore performed an implicit comparison with placebo. The variance of the random effects takes the variability between studies into account. Moreover, as several time points within a study are considered, this model takes also within study correlation into account. The comparison aimed to reveal different treatment responses in children compared to adults. This comparison is quantified using the odds ratio with a 95\% confidence interval. Additionally, the response probability adjusted for treatment and time is given with a 95\% confidence interval for each group. Calculations were performed with prpc glimmix, SAS 9.4.

\section{Results}

A comparative analysis using clinical and pharmacokinetic data was performed, based on data obtained from pivotal studies of biologics for the treatment of inflammation in children vs. adults and evaluated in terms of efficacy, safety and dose used. In total, one or two pivotal pediatric trials, and four to seven pivotal studies in adults for all biologics were identified. All drugs were given as either monotherapy or in combination with methotrexate, and either placebo-controlled or without control. The following section summarizes results (Tables 1-6) obtained from meta-analyses. 
Table 1a: Comparison of clinical trials with etanercept in children and adults.

\begin{tabular}{|c|c|c|c|c|c|c|c|c|c|c|}
\hline & \multirow{2}{*}{\multicolumn{2}{|c|}{$\begin{array}{c}\text { CHILDREN } \\
\text { Lovell, } 2000\end{array}$}} & \multicolumn{8}{|c|}{ ADULTS } \\
\hline \multirow[t]{2}{*}{$\begin{array}{c}\text { Study } \\
\text { Characteristics }\end{array}$} & & & \multicolumn{2}{|c|}{ Moreland, 1999} & \multicolumn{2}{|c|}{ Weinblatt, 1999} & \multicolumn{2}{|c|}{ Bathon, 2000} & \multicolumn{2}{|c|}{ Klareskog, 2004} \\
\hline & \multicolumn{2}{|c|}{ JIA-I } & \multicolumn{2}{|c|}{ Study I } & \multicolumn{2}{|c|}{ Study II } & \multicolumn{2}{|c|}{ Study III } & \multicolumn{2}{|c|}{ Study IV } \\
\hline Dosage & \multicolumn{2}{|c|}{$\begin{array}{l}\text { - } 0.4 \mathrm{mg} / \mathrm{Kg} \text { of body } \\
\text { weight subcutaneously } \\
\text { twice a week } \\
\text { (max. } 25 \mathrm{mg} \text { per dose) } \\
\text { - Placebo }\end{array}$} & \multicolumn{2}{|c|}{$\begin{array}{l}\text { - } 25 \text { mg subcutaneous } \\
\text { injections twice a week } \\
\text { - } 10 \mathrm{mg} \text { subcutaneous } \\
\text { injections twice a week } \\
\text { - Placebo }\end{array}$} & \multicolumn{2}{|c|}{$\begin{array}{c}\text { - } 25 \text { mg subcutaneous } \\
\text { injection twice a weekly } \\
\text { + MTX (12.5-25 mg/wk) } \\
\text { - Placebo + MTX (12.5-25 } \\
\text { mg/wk) }\end{array}$} & \multicolumn{2}{|c|}{$\begin{array}{c}\text { - } 25 \text { mg subcutaneous } \\
\text { injection twice a weekly } \\
\text { - } 10 \text { mg subcutaneous } \\
\text { injection twice a weekly } \\
\text { - Placebo + 7.5mg MTX } \\
\text { weekly }\end{array}$} & \multicolumn{2}{|c|}{$\begin{array}{l}\text { - } 25 \text { mg subcutaneously } \\
\text { twice a week } \\
\text { - } 25 \text { mg subcutaneously } \\
\text { twice a week + MTX (up } \\
\text { to } 20 \text { mg weekly) } \\
\text { - MTX (up to } 20 \mathrm{mg} \\
\text { weekly) }\end{array}$} \\
\hline $\begin{array}{l}\text { DMARDs during } \\
\text { study }\end{array}$ & \multicolumn{2}{|c|}{ Not permitted } & \multicolumn{2}{|c|}{ Not permitted } & \multicolumn{2}{|c|}{ Not permitted } & \multicolumn{2}{|c|}{ Not permitted } & \multicolumn{2}{|c|}{ Not permitted } \\
\hline Study duration & \multicolumn{2}{|c|}{$\begin{array}{l}\text { - open-label study: } 3 \\
\text { months - double-blind } \\
\text { study: } 4 \text { months (or until } \\
\text { flare) }\end{array}$} & \multicolumn{2}{|c|}{6 months } & \multicolumn{2}{|c|}{6 months } & \multicolumn{2}{|c|}{12 months } & \multicolumn{2}{|c|}{6 months } \\
\hline ACR results & \multicolumn{2}{|c|}{$\begin{array}{c}\text { Week 12(OL), Week } 16 \\
\text { (DB) }\end{array}$} & & & & & & 48 & & 24 \\
\hline ACR50 [\%] & OL study & 64 vs. Nd & $10 \mathrm{mg}$ & 24 vs. 5 & & & $10 \mathrm{mg}$ & 32 vs. 43 & $25 \mathrm{mg}$ & a 41 vs. 41 \\
\hline drug vs. placebo & DB study & 72 vs. 23 & $25 \mathrm{mg}$ & 40 vs. 5 & & & $25 \mathrm{mg}$ & 49 vs. 43 & $\begin{array}{l}25 \mathrm{mg}+ \\
\mathrm{MTX}\end{array}$ & a 59 vs. 41 \\
\hline ACR70 [\%] & OL study & 36 vs. $\mathrm{Nd}$ & $10 \mathrm{mg}$ & 9 vs. 1 & & & $10 \mathrm{mg}$ & 16 vs. 22 & $25 \mathrm{mg}$ & a 17 vs. 15 \\
\hline drug vs. placebo & DB study & 44 vs. 19 & $25 \mathrm{mg}$ & 15 vs. 1 & & & $25 \mathrm{mg}$ & 25 vs. 22 & $\begin{array}{l}25 \mathrm{mg}+ \\
\mathrm{MTX}\end{array}$ & a 36 vs. 15 \\
\hline AEs and SAEs & & & & & & & & & & \\
\hline Most frequently & No. (\%) & patients & $\%$ Of adv & e events & $\%$ Of & & No. (\%) & patients & No. $(\%)$ & patients \\
\hline & & & $25 \mathrm{mg}$ & 49 & $25 \mathrm{mg}$ & 42 & $25 \mathrm{mg}$ & 77 (37) & $25 \mathrm{mg}$ & $46(21)$ \\
\hline $\begin{array}{l}\text { Injection site } \\
\text { reaction }\end{array}$ & $\begin{array}{r}\text { OL (39); } \\
\text { plc }\end{array}$ & $\begin{array}{l}\text { B (1); DB } \\
\text { (1) }\end{array}$ & $10 \mathrm{mg}$ & 43 & placebo & 7 & $10 \mathrm{mg}$ & $63(30)$ & $\begin{array}{c}25 \mathrm{mg}+ \\
\mathrm{MTX}\end{array}$ & $23(10)$ \\
\hline & & & placebo & 13 & & & placebo & $16(7)$ & placebo & $4(2)$ \\
\hline & & & $25 \mathrm{mg}$ & 14 & $25 \mathrm{mg}$ & 20 & $25 \mathrm{mg}$ & $46(22)$ & $25 \mathrm{mg}$ & $34(15)$ \\
\hline Headache & OL $(20)$ & l.a. ; n.a. & $10 \mathrm{mg}$ & 20 & placebo & 17 & $10 \mathrm{mg}$ & $52(25)$ & $\begin{array}{l}25 \mathrm{mg}+ \\
\mathrm{MTX}\end{array}$ & $34(15)$ \\
\hline & & & placebo & 10 & & & placebo & $59(27)$ & placebo & $31(14)$ \\
\hline Upper & & & $25 \mathrm{mg}$ & 33 & & & $25 \mathrm{mg}$ & $72(35)$ & & \\
\hline respiratory tract & OL $(35)$ & 1.a. ; n.a. & $10 \mathrm{mg}$ & 29 & n.a. & & $10 \mathrm{mg}$ & $57(27)$ & n.a. & \\
\hline infection & & & placebo & 16 & & & placebo & $84(39)$ & & \\
\hline & & & $25 \mathrm{mg}$ & 10 & $25 \mathrm{mg}$ & 14 & $25 \mathrm{mg}$ & $31(15)$ & & \\
\hline Rhinitis & OL $(16)$ & 1.a. ; n.a. & $10 \mathrm{mg}$ & 12 & placebo & 3 & $10 \mathrm{mg}$ & $36(17)$ & n.a. & \\
\hline & & & placebo & 11 & & & placebo & $30(14)$ & & \\
\hline & & & & & $25 \mathrm{mg}$ & 10 & $25 \mathrm{mg}$ & $35(17)$ & $25 \mathrm{mg}$ & $22(10)$ \\
\hline Nausea & OL $(12)$ & 1.a. ; n.a. & & & placebo & 23 & $10 \mathrm{mg}$ & $29(14)$ & $\begin{array}{l}25 \mathrm{mg}+ \\
\mathrm{MTX}\end{array}$ & $55(24)$ \\
\hline & & & & & & & placebo & $62(29)$ & placebo & $73(32)$ \\
\hline & & & & & & & $25 \mathrm{mg}$ & $50(23)$ & $25 \mathrm{mg}$ & $16(7)$ \\
\hline Rash & OL (10) & l.a. ; n.a. & & & & & $10 \mathrm{mg}$ & 33 (16) & $\begin{array}{c}25 \mathrm{mg}+ \\
\mathrm{MTX}\end{array}$ & 23 (10) \\
\hline & & & & & & & placebo & $50(23)$ & placebo & $21(9)$ \\
\hline
\end{tabular}




\section{Abbreviations: \\ n.a: not available \\ OL: open label \\ DB: double-blind \\ MTX: Methotrexate}

Table 1b: Pharmacology data of clinical trials with etanercept in children and adults.

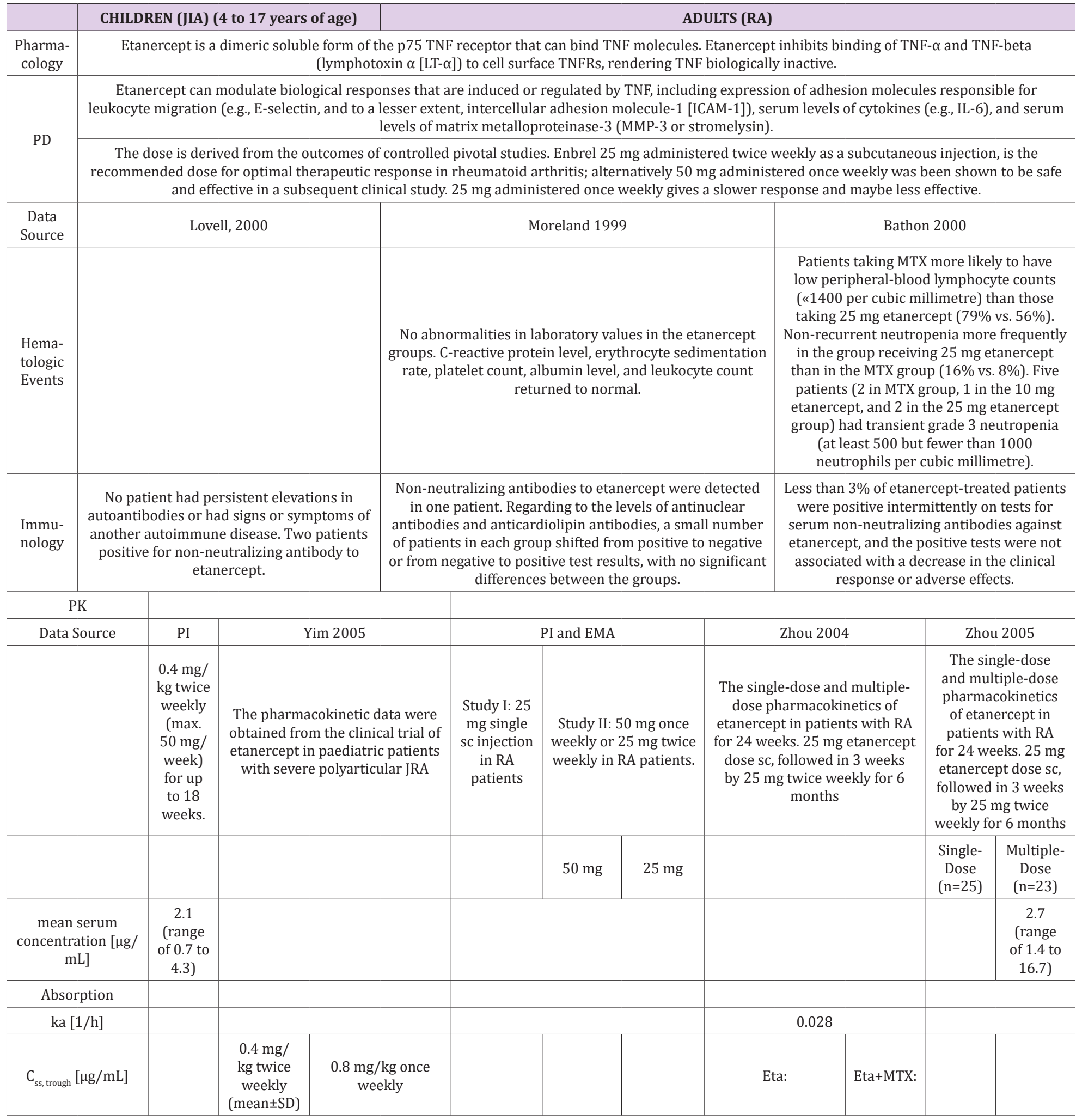




\begin{tabular}{|c|c|c|c|c|c|c|c|c|c|}
\hline & $1.92 \pm 1.09$ & \multirow{2}{*}{$\begin{array}{l}(\text { mean } \pm \text { SD) } \\
1.58 \pm 1.07\end{array}$} & & & & $2.0 \pm 0.1$ & $\begin{array}{l}2.26 \pm \\
0.08\end{array}$ & & \\
\hline & & & & & & & & & \\
\hline \multirow{2}{*}{$\mathrm{C}_{\text {max }}[\mu \mathrm{g} / \mathrm{mL}]$} & $2.62 \pm 1.23$ & $2.92 \pm 1.41$ & $($ mean \pm SD $)$ & $2.4 \pm 1.5$ & $2.6 \pm 1.2$ & & & $\begin{array}{l}1.072 \pm \\
0.635\end{array}$ & $2.4 \pm 0.99$ \\
\hline & & & $1.1 \pm 0.6$ & & & & & & \\
\hline $\mathrm{C}_{\min }[\mu \mathrm{g} / \mathrm{mL}]$ & & & & $1.2 \pm 0.7$ & $1.4 \pm 0.7$ & & & & \\
\hline \multirow{2}{*}{$\mathrm{T}_{\max }[\mathrm{h}]$} & & & $($ mean \pm SD $)$ & & & & & $\begin{array}{c}69.2 \pm \\
33.8\end{array}$ & $\begin{array}{c}32.1 \pm \\
27.3 \\
\end{array}$ \\
\hline & & & $69 \pm 34$ & & & & & & \\
\hline $\begin{array}{l}\text { average absolute } \\
\text { bioavailability [\%] }\end{array}$ & & & 76 & & & 62.6 & & & \\
\hline 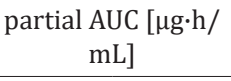 & & & & $297 \pm 166$ & $316 \pm 135$ & & & $\begin{array}{l}\text { a201.7 } \\
\pm 94.3\end{array}$ & $\begin{array}{c}\text { a143.6 } \\
57.2\end{array}$ \\
\hline \multicolumn{10}{|l|}{ Distribution } \\
\hline $\mathrm{V}_{\mathrm{sS}}[\mathrm{L}]$ & 7.88 & & $\begin{array}{l}10.4 \text { (for } \\
\text { a } 70 \mathrm{~kg} \\
\text { subject) }\end{array}$ & & & & & & \\
\hline$V_{c}[L]$ & & & & & & 5.97 & & & \\
\hline $\mathrm{V}_{\mathrm{p}}[\mathrm{L}]$ & & & & & & 2.05 & & & \\
\hline \multicolumn{10}{|l|}{ Elimination } \\
\hline \multirow[t]{2}{*}{$\mathrm{C}_{1}[\mathrm{~mL} / \mathrm{h}]$} & \multicolumn{2}{|c|}{$\begin{array}{l}\text { (Calculated for a subject with } \\
\text { BSA } 1.071 \mathrm{~m} 2 \text { and body weight } \\
30.8 \mathrm{~kg} \text { (median values)): }\end{array}$} & $($ mean \pm SD) & & & 72 & & & \\
\hline & \multicolumn{2}{|c|}{ Female: 57.6 / Male: 77.2} & $160 \pm 80$ & & & & & & \\
\hline $\mathrm{Q}[\mathrm{mL} / \mathrm{h}]$ & & & & & & 65 & & & \\
\hline \multirow[t]{2}{*}{ half-life [days] } & \multicolumn{2}{|c|}{$\begin{array}{l}\text { (calculated for a subject weighing } \\
\qquad 30.8 \mathrm{~kg} \text { ): }\end{array}$} & $($ mean $\pm S D)$ & & & & & $\begin{array}{c}102.3 \pm \\
30.1\end{array}$ & $\begin{array}{c}93.7 \pm \\
18.6\end{array}$ \\
\hline & \multicolumn{2}{|c|}{ Female: $\sim 4$ / Male: $\sim 3$} & $102 \pm 30$ & & & & & & \\
\hline
\end{tabular}

Abbreviations:

PD: Pharmacodynamics

PK: Pharmacokinetics

ka: First-order absorption rate constant

$\mathrm{C}_{\mathrm{ss} \text {, trough }}$ : steady-state trough concentration

$\mathrm{C}_{\max }:$ Maximum serum concentration

$\mathrm{C}_{\text {min }}:$ Minimum serum concentration

$\mathrm{T}_{\max }$ : Time to reach the maximum concentration

$\mathrm{V}_{\mathrm{ss}}$ : Distribution volume

$\mathrm{V}_{\mathrm{c}}$ : Volume of distribution in the central compartment

$\mathrm{V}_{\mathrm{p}}$ : Volume of distribution in the peripheral compartment

$\mathrm{C}_{\mathrm{L}}$ : Clearance

Q: Intercompartment clearance 
Table 2a: Comparison of clinical trials with adalimumab in children and adults.

\begin{tabular}{|c|c|c|c|c|c|c|c|c|c|c|c|c|c|}
\hline & \multicolumn{5}{|c|}{ CHILDREN } & \multicolumn{8}{|c|}{ ADULTS } \\
\hline \multirow{2}{*}{$\begin{array}{l}\text { Study } \\
\text { Charac- } \\
\text { teristics }\end{array}$} & \multicolumn{3}{|c|}{ Lovell, 2008} & \multicolumn{2}{|c|}{ Kingsbury, 2014} & \multicolumn{2}{|c|}{ Weinblatt, 2003} & \multicolumn{2}{|c|}{ Van de Putte, 2004} & \multicolumn{3}{|c|}{ Keystone, 2004} & Furst, 2003 \\
\hline & \multicolumn{3}{|c|}{ PJIA-I } & \multicolumn{2}{|c|}{ PJIA-II } & \multicolumn{2}{|c|}{ RA-I } & \multicolumn{2}{|c|}{ RA-II } & \multicolumn{3}{|c|}{ RA-III } & RA-IV \\
\hline Dosage & \multicolumn{3}{|c|}{$\begin{array}{l}\text { - Subcutaneous injection } 24 \\
\text { mg/ } \text { m }^{2} \text { body-surface area } \\
\text { (max. } 40 \mathrm{mg} \text { ) } \pm \text { MTX } \\
\text { - Placebo } \pm \text { MTX }\end{array}$} & \multicolumn{2}{|c|}{$\begin{array}{l}\text { - Subcutaneous } \\
\text { injection } 24 \mathrm{mg} / \mathrm{m}^{2} \\
\text { every other week } \\
\text { (max. } 20 \mathrm{mg} / \text { dose) } \\
\pm \text { MTX }\end{array}$} & \multicolumn{2}{|c|}{$\begin{array}{l}\text { - Subcutaneous } \\
\text { injections } 20 \mathrm{mg} \text {, } \\
40 \mathrm{mg} \text {, or } 80 \mathrm{mg} \\
\text { every other week } \\
\text { + MTX. } \\
\text { - Placebo + MTX }\end{array}$} & \multicolumn{2}{|c|}{$\begin{array}{c}\text { - Subcutaneous } \\
\text { injections } 20 \mathrm{mg} \\
\text { every other week, } \\
20 \text { mg weekly, } 40 \\
\text { mg every other } \\
\text { week, } 40 \text { mg weekly, } \\
\text { or placebo. }\end{array}$} & \multicolumn{3}{|c|}{$\begin{array}{c}\text { - Subcutaneous injections at } \\
40 \text { mg every other week + } \\
\text { MTX or } \\
20 \text { mg every week + MTX } \\
\text { - Placebo + MTX }\end{array}$} & $\begin{array}{l}\text { - Subcutaneous } \\
\text { injections } 40 \\
\text { mg every other } \\
\text { week. } \\
\text { - Placebo }\end{array}$ \\
\hline $\begin{array}{l}\text { NSAIDs } \\
\text { and/or } \\
\text { cortico- } \\
\text { steroids }\end{array}$ & \multicolumn{3}{|c|}{ Permitted } & \multicolumn{2}{|c|}{$\begin{array}{l}\text { Permitted; No } \\
\text { DMARDs }\end{array}$} & \multicolumn{2}{|c|}{$\begin{array}{l}\text { Permitted; No } \\
\text { DMARDs }\end{array}$} & \multicolumn{2}{|c|}{$\begin{array}{l}\text { Allowed before the } \\
\text { study. No DMARDs }\end{array}$} & \multicolumn{3}{|c|}{ Permitted; No DMARDs } & $\begin{array}{l}\text { Permitted; } \\
\text { DMARDs } \\
\text { permitted }\end{array}$ \\
\hline \multirow[t]{2}{*}{$\begin{array}{c}\text { Study } \\
\text { dura- } \\
\text { tion }\end{array}$} & \multicolumn{3}{|c|}{ - open label study: 16 weeks } & \multicolumn{2}{|c|}{ Up to 120 weeks } & \multirow{2}{*}{\multicolumn{2}{|c|}{24 weeks }} & \multirow{2}{*}{\multicolumn{2}{|c|}{26 weeks }} & \multirow{2}{*}{\multicolumn{3}{|c|}{52 weeks }} & \multirow[t]{2}{*}{24 weeks } \\
\hline & - double & $\begin{array}{l}\text { lind stu } \\
\text { otal } 48 \mathrm{n}\end{array}$ & $\begin{array}{l}32 \text { weeks. } \\
\text { ks) }\end{array}$ & open-la & tudy & & & & & & & & \\
\hline $\begin{array}{l}\text { ACR } \\
\text { results }\end{array}$ & Week 1 & $(\mathrm{OL}), \mathrm{We}$ & 48 (DB)a & $\begin{array}{r}\text { Observe } \\
\text { at weeks } \\
\text { an }\end{array}$ & $\begin{array}{l}\text { nalysis } \\
24,60 \text {, } \\
6\end{array}$ & Wee & 24 & We & 26 & Wee & 24 and & k 52 & Week 24 \\
\hline $\begin{array}{c}\text { ACR50 } \\
{[\%]}\end{array}$ & $\begin{aligned} & \text { OL } \\
+ & \mathrm{MTX}\end{aligned}$ & & s. n.a. & $\begin{array}{l}\text { Week } \\
12\end{array}$ & 90 & $20 \mathrm{mg}$ & 22 vs. 5 & $\begin{array}{l}20 \mathrm{mg} \\
\text { every } \\
\text { other } \\
\text { week. }\end{array}$ & 20 vs. 9 & w24 & $40 \mathrm{mg}$ & $\begin{array}{l}81 \text { vs. } \\
19\end{array}$ & \\
\hline $\begin{array}{l}\text { drug vs. } \\
\text { placebo }\end{array}$ & $\begin{array}{l}\text { OL - } \\
\text { MTX }\end{array}$ & & s. n.a. & $\begin{array}{l}\text { Week } \\
24\end{array}$ & 83 & $40 \mathrm{mg}$ & 37 vs. 5 & $\begin{array}{l}20 \mathrm{mg} \\
\text { wkly. }\end{array}$ & 23 vs. 9 & w24 & $20 \mathrm{mg}$ & $\begin{array}{c}87 \text { vs. } \\
19\end{array}$ & 28.9 vs. 11.3 \\
\hline & $\begin{array}{c}\text { DB } \\
+ \text { MTX }\end{array}$ & & s. 38 & $\begin{array}{l}\text { Week } \\
60\end{array}$ & 80 & $80 \mathrm{mg}$ & 31 vs. 5 & $\begin{array}{l}\text { 40mg } \\
\text { e.o.w. }\end{array}$ & 25 vs. 9 & w52 & $40 \mathrm{mg}$ & $\begin{array}{c}86 \text { vs. } \\
19\end{array}$ & \\
\hline & $\begin{array}{c}\text { DB } \\
\text {-MTX }\end{array}$ & & s. 32 & $\begin{array}{l}\text { Week } \\
96\end{array}$ & 92 & & & $\begin{array}{l}40 \mathrm{mg} \\
\text { wkly. }\end{array}$ & 36 vs. 9 & w52 & $20 \mathrm{mg}$ & $\begin{array}{c}80 \text { vs. } \\
19\end{array}$ & \\
\hline $\begin{array}{c}\text { ACR70 } \\
{[\%]}\end{array}$ & $\begin{aligned} & \text { OL } \\
+ & \text { MTX }\end{aligned}$ & & s. n.a. & $\begin{array}{l}\text { Week } \\
12\end{array}$ & 61 & $20 \mathrm{mg}$ & 7 vs. 3 & $\begin{array}{l}20 \mathrm{mg} \\
\text { every } \\
\text { other } \\
\text { week. }\end{array}$ & 9 vs. 2 & w24 & $40 \mathrm{mg}$ & 43 vs. 5 & \\
\hline $\begin{array}{l}\text { drug vs. } \\
\text { placebo }\end{array}$ & $\begin{array}{l}\text { OL - } \\
\text { MTX }\end{array}$ & & s. n.a. & $\begin{array}{c}\text { Week } \\
24\end{array}$ & 73 & $40 \mathrm{mg}$ & 18 vs. 3 & $\begin{array}{l}20 \mathrm{mg} \\
\text { wkly. }\end{array}$ & 11 vs. 2 & w24 & $20 \mathrm{mg}$ & 37 vs. 5 & \\
\hline & $\begin{aligned} & \text { DB } \\
+ & \text { MTX }\end{aligned}$ & & s. 27 & $\begin{array}{l}\text { Week } \\
60\end{array}$ & 70 & $80 \mathrm{mg}$ & 14 vs. 3 & $\begin{array}{l}40 \mathrm{mg} \\
\text { every } \\
\text { other } \\
\text { week }\end{array}$ & 14 vs. 2 & w52 & $40 \mathrm{mg}$ & 48 vs. 9 & \\
\hline & $\begin{array}{c}\text { DB } \\
-\mathrm{MTX}\end{array}$ & & s. 29 & $\begin{array}{l}\text { Week } \\
96\end{array}$ & 77 & & & $\begin{array}{l}40 \mathrm{mg} \\
\text { wkly. }\end{array}$ & 19 vs. 2 & w52 & $20 \mathrm{mg}$ & 44 vs. 9 & \\
\hline $\begin{array}{l}\text { AEs and } \\
\text { AEs }\end{array}$ & & & & & & & & & & & & & \\
\hline $\begin{array}{l}\text { Most } \\
\text { fre- } \\
\text { quently }\end{array}$ & & $(\%)$ of $p$ & ents & No. $(\%)$ & atients & No. $(\%)$ & patients & No. (\%) & patients & & (\%) of $\mathrm{p}$ & nts & $\begin{array}{l}\text { No. (\%) of } \\
\text { patients }\end{array}$ \\
\hline & Place & o+MTX & 57 (3.8) & & & Placebo & 0 & Placebo & $1(0.9)$ & Placebo & & & Placebo \\
\hline & Place & o-MTX & 20 (1.9) & & & $20 \mathrm{mg}$ & $3(4.3)$ & $\begin{array}{l}\text { Ada } \\
\text { groups }\end{array}$ & $46(10.6)$ & $20 \mathrm{mg}$ & & 2.2) & $40 \mathrm{mg}$ \\
\hline tion site & $\mathrm{OL}$ & MTX & $142(5.2)$ & & & $40 \mathrm{mg}$ & $1(1.5)$ & & & $40 \mathrm{mg}$ & & $6.1)$ & \\
\hline reaction & OL & MTX & $166(5.7)$ & & & $80 \mathrm{mg}$ & 8 (11) & & & & & & \\
\hline & DB & MTX & $73(4.0)$ & & & & & & & & & & \\
\hline & DB & MTX & $71(4.9)$ & & & & & & & & & & \\
\hline
\end{tabular}




\begin{tabular}{|c|c|c|c|c|c|c|c|c|c|c|}
\hline \multirow{6}{*}{$\begin{array}{c}\text { Upper } \\
\text { respi- } \\
\text { ratory } \\
\text { tract } \\
\text { infec- } \\
\text { tion }\end{array}$} & Placebo+MTX & $5(0.3)$ & \multirow{6}{*}{$6(19)$} & Placebo & $6(9.7)$ & Placebo & n.a. & Placebo & $27(13.5)$ & Placebo \\
\hline & Placebo-MTX & $6(0.6)$ & & $20 \mathrm{mg}$ & $\begin{array}{c}14 \\
(20.3)\end{array}$ & $\begin{array}{l}\text { Ada } \\
\text { groups }\end{array}$ & n.a. & $20 \mathrm{mg}$ & $41(19.3)$ & $40 \mathrm{mg}$ \\
\hline & $\mathrm{OL}+\mathrm{MTX}$ & $9(0.3)$ & & $40 \mathrm{mg}$ & $\begin{array}{c}10 \\
(14.9)\end{array}$ & & & $40 \mathrm{mg}$ & 41 (19.8) & \\
\hline & OL -MTX & $11(0.4)$ & & $80 \mathrm{mg}$ & $\begin{array}{c}16 \\
(21.9)\end{array}$ & & & & & \\
\hline & $\mathrm{DB}+\mathrm{MTX}$ & $6(0.3)$ & & & & & & & & \\
\hline & DB -MTX & $6(0.4)$ & & & & & & & & \\
\hline
\end{tabular}

Table 2b: Pharmacology data of clinical trials with adalimumab in children and adults.

\begin{tabular}{|c|c|c|c|c|c|c|}
\hline & \multicolumn{2}{|c|}{ CHILDREN (JIA) ( 4 to 17 years of age) } & \multicolumn{4}{|c|}{ ADULTS (RA) } \\
\hline $\begin{array}{l}\text { Pharmacol- } \\
\text { ogy }\end{array}$ & \multicolumn{6}{|c|}{$\begin{array}{l}\text { Blocks interaction of human TNF- } \alpha \text { with receptors and modulates biological responses induced or regulated by TNF (changes in the levels of } \\
\text { adhesion molecules responsible for leukocyte migration (ELAM-1, VCAM-1, and ICAM-1 with an IC50 of 1-2 X 10-10M). It does not bind or inactivate } \\
\text { lymphotoxin (TNF-beta). }\end{array}$} \\
\hline \multirow[t]{2}{*}{ PD } & \multicolumn{6}{|c|}{$\begin{array}{c}\text { - Decrease in levels of acute phase reactants of inflammation (C-reactive protein (CRPJ and erythrocyte sedimentation rate (ESRJ) and serum } \\
\text { cytokines (IL-6). }\end{array}$} \\
\hline & \multicolumn{6}{|c|}{ - Decrease in serum levels of matrix metalloproteinases (MMP-1 and MMP-3) that produce tissue remodelling responsible for cartilage destruction. } \\
\hline Data Source & Lovell 2008 & Kingsbury 2014 & Weinblatt 2003 & $\begin{array}{l}\text { Van de Putte } \\
2004\end{array}$ & Keystone 2004 & Furst 2003 \\
\hline $\begin{array}{l}\text { Hematologic } \\
\text { Events }\end{array}$ & & & \multicolumn{2}{|c|}{$\begin{array}{c}\text { The hematocrit value, } \\
\text { haemoglobin concentration, } \\
\text { and percentage of lymphocytes } \\
\text { showed increases, and the platelet } \\
\text { count showed a decrease. }\end{array}$} & $\begin{array}{l}\text { Adalimumab } \\
\text { therapy was } \\
\text { associated with } \\
\text { statistically sig- } \\
\text { nificant decreas- } \\
\text { es (compared } \\
\text { with baseline } \\
\text { values) in the } \\
\text { mean white } \\
\text { blood cell count, } \\
\text { platelet count, } \\
\text { and neutrophil } \\
\text { percentage, as } \\
\text { well as statis- } \\
\text { tically signifi- } \\
\text { cant increases } \\
\text { (compared with } \\
\text { baseline values) } \\
\text { in the mean } \\
\text { haemoglobin } \\
\text { concentration, } \\
\text { hematocrit, and } \\
\text { lymphocyte } \\
\text { percentage (data } \\
\text { not shown), } \\
\text { with all of these } \\
\text { indices moving } \\
\text { toward more } \\
\text { normal values. } \\
\text { In the placebo } \\
\text { group, changes } \\
\text { in all of these pa- } \\
\text { rameters were of } \\
\text { less magnitude } \\
\text { and were not } \\
\text { statistically sig- } \\
\text { nificant for the } \\
\text { platelet count } \\
\text { and lymphocyte } \\
\text { percentage. }\end{array}$ & $\begin{array}{c}\text { Mean } \\
\text { changes in } \\
\text { haematology } \\
\text { values were } \\
\text { comparable } \\
\text { between the } \\
\text { adalimumab } \\
\text { and placebo } \\
\text { groups. } \\
\text { Overall, the } \\
\text { mean chang- } \\
\text { es for all } \\
\text { biochemis- } \\
\text { try variables } \\
\text { were small } \\
\text { and were } \\
\text { comparable } \\
\text { for patients } \\
\text { treated with } \\
\text { adalimumab } \\
\text { and placebo. }\end{array}$ \\
\hline
\end{tabular}




\begin{tabular}{|c|c|c|c|c|c|c|c|c|c|}
\hline Immunology & $\begin{array}{l}16 \% \text { patient } \\
\text { for anti-adal } \\
\text { open-label } \\
\text { receiving MT } \\
\text { Development o } \\
\text { not lead to a gr }\end{array}$ & $\begin{array}{l}\text { at leas } \\
\text { mab an } \\
\text { louble- } \\
\text { d } 26 \% \\
\text { i-adalir } \\
\text { r rate o } \\
\text { study o }\end{array}$ & $\begin{array}{l}\text { je test } \\
\text { g the } \\
: 6 \% \\
\text { MTX. } \\
\text { oody did } \\
\text { ation of }\end{array}$ & $\begin{array}{r}\text { Am } \\
\text { wl } \\
\text { phar } \\
\text { only } \\
\text { dev } \\
\text { the }\end{array}$ & $\begin{array}{l}5 \text { patients } \\
\text { mples for } \\
\text { tic analysis, } \\
\text { ent ( } 6.7 \%) \\
\text { A+ during } \\
\text { that were } \\
\text { ted. }\end{array}$ & & $\begin{array}{l}\text { Over the course } \\
\text { of the study, } \\
12 \% \text { of adalim- } \\
\text { umab treated } \\
\text { patients tested } \\
\text { positive for } \\
\text { antibodies } \\
\text { against adalim- } \\
\text { umab; however, } \\
\text { there were no } \\
\text { differences in } \\
\text { the pattern or } \\
\text { frequency of } \\
\text { adverse events } \\
\text { between pa- } \\
\text { tients with or } \\
\text { without these } \\
\text { antibodies }\end{array}$ & $\begin{array}{l}\text { Two patients } \\
\text { in the group } \\
\text { receiving } \\
\text { adalimumab } \\
40 \text { mg every } \\
\text { other week, } 1 \\
\text { patient in the } \\
\text { group receiving } \\
\text { adalimumab } 20 \\
\text { mg weekly, and } \\
1 \text { patient in the } \\
\text { placebo group } \\
\text { were positive for } \\
\text { anti-adalimumab } \\
\text { antibodies on at } \\
\text { least } 1 \text { occasion. }\end{array}$ & \\
\hline PK & & & & & & & & & \\
\hline Data Source & $\mathrm{P}$ & & & ngsbu & & & & Nestorov & 2005 \\
\hline & & & & & & In RA patients & ceiving $40 \mathrm{mg}$ & $\begin{array}{l}\text { PK data for adali } \\
\text { been published i } \\
\text { and are summa } \\
\text { revie }\end{array}$ & $\begin{array}{l}\text { mumab have } \\
\text { RA patients } \\
\text { ized in this } \\
N .\end{array}$ \\
\hline & & & & & & HUMIRA ev & ther week & $\begin{array}{r}\text { Adalimumab is a } \\
\text { subcutaneously (s } \\
\text { uniform multiple } \\
\text { other w }\end{array}$ & $\begin{array}{l}\text { dministered } \\
\text { c) by a } 40 \mathrm{mg} \\
\text { dosing every } \\
\text { eek. }\end{array}$ \\
\hline & $\begin{array}{c}20 \mathrm{mg} \\
\text { monotherapy }\end{array}$ & 6.8 & Monoth & rapy: & Ada+MTX: & monotherapy & 5 & $5.5 \pm 2$ & \\
\hline $\begin{array}{l}\text { mean serum } \\
\text { concentra- }\end{array}$ & $\begin{array}{c}20 \mathrm{mg}+ \\
\text { methotrexate }\end{array}$ & 10.9 & & & & $\begin{array}{c}\text { with } \\
\text { methotrexate }\end{array}$ & $8-9$ & & \\
\hline $\begin{array}{c}\text { tion }[\mu \mathrm{g} / \\
\mathrm{mL}]\end{array}$ & $\begin{array}{c}40 \mathrm{mg} \\
\text { monotherapy }\end{array}$ & 6.6 & 6 & & $7-8$ & & & & \\
\hline & $\begin{array}{c}40 \mathrm{mg}+ \\
\text { methotrexate }\end{array}$ & 8.1 & & & & & & & \\
\hline Absorption & & & & & & $\begin{array}{r}\text { Single } 40 \mathrm{~m} \\
\text { injection to hea }\end{array}$ & $\begin{array}{l}\text { ubcutaneous } \\
\text { y adult subjects }\end{array}$ & & \\
\hline ka [1/h] & & & & & & & & & \\
\hline $\begin{array}{c}\mathrm{C}_{\mathrm{ss}, \text { trough }}[\mu \mathrm{g} / \\
\mathrm{mL}]\end{array}$ & & & & & & & & & \\
\hline $\mathrm{C}_{\max }[\mu \mathrm{g} / \mathrm{mL}]$ & & & & & & $4.7 \pm 1.6$ & & $7.7 \pm 3.4$ & \\
\hline$C_{\min }[\mu \mathrm{g} / \mathrm{mL}]$ & & & & & & & & $3.8 \pm 2.1$ & \\
\hline $\mathrm{T}_{\text {max }}[\mathrm{h}]$ & & & & & & $131 \pm 56$ & & $90 \pm 48$ & \\
\hline $\begin{array}{c}\text { average } \\
\text { absolute bio- } \\
\text { availability } \\
{[\%]}\end{array}$ & & & & & & 64 & & & \\
\hline $\begin{array}{c}\mathrm{AUC}_{0-\mathrm{T}}[\mathrm{mg} \\
\mathrm{h} / \mathrm{L}]\end{array}$ & & & & & & & & $1830 \pm 850$ & \\
\hline Distribution & & & & & & & & & \\
\hline $\mathrm{V}_{\mathrm{sS}}[\mathrm{L}]$ & & & & & & 4.7 to 6 & & & \\
\hline$V_{c}[L]$ & & & & & & & & & \\
\hline $\mathrm{V}_{\mathrm{p}}[\mathrm{L}]$ & & & & & & & & & \\
\hline Elimination & & & & & & & & & \\
\hline $\mathrm{Cl}[\mathrm{mL} / \mathrm{h}]$ & . & & & & & 12 & & & \\
\hline
\end{tabular}




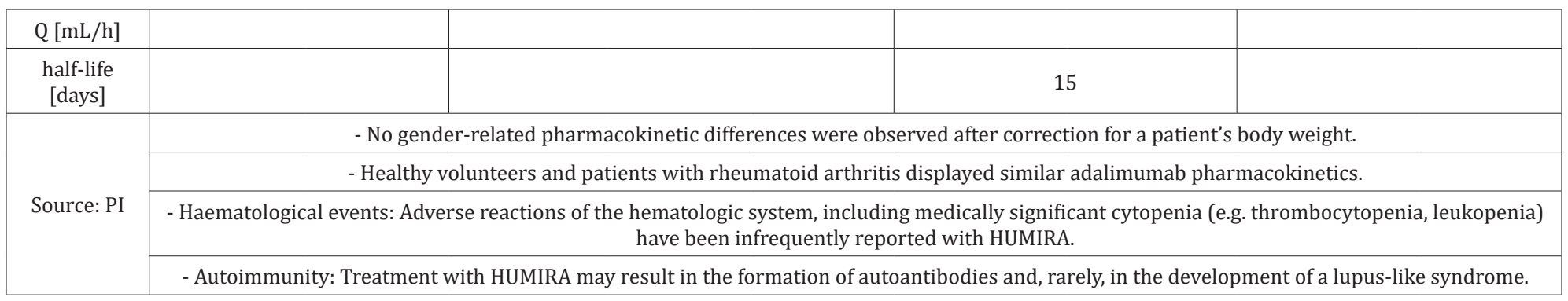

Table 3a: Comparison of clinical trials with infliximab in children and adults.

\begin{tabular}{|c|c|c|c|c|c|c|c|c|c|c|c|}
\hline & \multirow{2}{*}{\multicolumn{4}{|c|}{$\begin{array}{c}\text { Children } \\
\text { Ruperto, } 2007\end{array}$}} & \multicolumn{7}{|c|}{ Adults } \\
\hline $\begin{array}{c}\text { 1. Study } \\
\text { Characteristics }\end{array}$ & & & & & \multicolumn{5}{|c|}{ Maini, 1999} & \multicolumn{2}{|c|}{ St Clair, 2004} \\
\hline Dosage & \multicolumn{4}{|c|}{$\begin{array}{c}\text { Infusion of infliximab } 3 \mathrm{mg} / \mathrm{kg}(+\mathrm{MTX}) \text { for } \\
44 \text { weeks or placebo for } 14 \mathrm{weeks} \text { followed } \\
\text { by MTX + infliximab } 6 \mathrm{mg} / \mathrm{kg}(+\mathrm{MTX}) \\
\text { through week } 44\end{array}$} & $\begin{array}{l}\text { Intraven } \\
\text { kg, +MTX }\end{array}$ & $\begin{array}{l}\text { inflixir } \\
\text { ery } 4\end{array}$ & $\begin{array}{l}\text { b injection } \\
8 \text { weeks th } \\
\text { acebo }+M\end{array}$ & $\begin{array}{l}(3 \mathrm{mg} / \mathrm{kg} \mathrm{c} \\
\text { ough week } \\
\mathrm{X}\end{array}$ & $\begin{array}{l}10 \mathrm{mg} / \\
30 \text { versus }\end{array}$ & \multicolumn{2}{|c|}{$\begin{array}{c}\text { Infusion of placebo } \\
(+\mathrm{MTX}), 3 \mathrm{mg} / \\
\text { kg infliximab } \\
(+\mathrm{MTX}), \text { or } 6 \mathrm{mg} / \mathrm{kg} \\
\text { infliximab }(+\mathrm{MTX}) \\
\text { at weeks } 0,2 \text {, and } 6 \text {, } \\
\text { and q8w thereafter } \\
\text { through week } 46\end{array}$} \\
\hline $\begin{array}{l}\text { DMARDs, } \\
\text { NSAIDs and/or } \\
\text { corticosteroids } \\
\text { during study }\end{array}$ & \multicolumn{4}{|c|}{$\begin{array}{l}\text { MTX and intraarticular corticosteroid } \\
\text { injections allowed }\end{array}$} & \multicolumn{5}{|c|}{ MTX and NSAIDs allowed } & \multicolumn{2}{|c|}{$\begin{array}{l}\text { MTX, oral } \\
\text { corticosteroids and } \\
\text { NSAIDs }\end{array}$} \\
\hline Study duration & \multicolumn{4}{|c|}{44 weeks } & \multicolumn{5}{|c|}{30 weeks } & \multicolumn{2}{|c|}{54 weeks } \\
\hline \multicolumn{12}{|l|}{ 2. ACR Results } \\
\hline & & & & & \multicolumn{5}{|c|}{ Week 30} & \multicolumn{2}{|c|}{ Week 54} \\
\hline ACR50 & & \multicolumn{2}{|c|}{$\mathrm{P} / 6 \mathrm{mg} / \mathrm{kg}$} & $3 \mathrm{mg} / \mathrm{kg}$ & $\begin{array}{c}3 \mathrm{mg} / \mathrm{kg} \\
\mathrm{q} 8 \mathrm{w}\end{array}$ & \multicolumn{2}{|c|}{$3 \mathrm{mg} / \mathrm{kg} \mathrm{q} 4 \mathrm{w}$} & $\begin{array}{c}10 \mathrm{mg} / \mathrm{kg} \\
\mathrm{q} 8 \mathrm{w}\end{array}$ & $\begin{array}{c}10 \mathrm{mg} / \mathrm{kg} \\
\mathrm{q} 4 \mathrm{w}\end{array}$ & $3 \mathrm{mg} / \mathrm{kg}$ & $6 \mathrm{mg} / \mathrm{kg}$ \\
\hline \multirow{2}{*}{$\begin{array}{l}\text { drug vs. placebo [n } \\
(\%)]\end{array}$} & Week 14 & \multicolumn{2}{|c|}{ 20/59 (33.9) } & $\begin{array}{c}29 / 58 \\
(50)\end{array}$ & $\begin{array}{l}22(27) \\
\text { vs. }\end{array}$ & \multicolumn{2}{|c|}{25 (29) vs. } & $\begin{array}{l}26(31) \\
\text { vs. }\end{array}$ & $\begin{array}{l}21(26) \\
\text { vs. }\end{array}$ & $\begin{array}{c}\text { (45.6) vs. } \\
(32.1) \mathrm{c}\end{array}$ & $\begin{array}{c}\text { (50.4) vs. } \\
(32.1)\end{array}$ \\
\hline & Week 52 & \multicolumn{2}{|c|}{$78 / 112(69.9)$} & & $4(5) c$ & \multicolumn{2}{|c|}{$4(5) c$} & $4(5) c$ & $4(5) c$ & & \\
\hline ACR70 & & \multicolumn{2}{|c|}{$\mathrm{P} / 6 \mathrm{mg} / \mathrm{kg}$} & $3 \mathrm{mg} / \mathrm{kg}$ & $\begin{array}{c}3 \mathrm{mg} / \mathrm{kg} \\
\mathrm{q} 8 \mathrm{w}\end{array}$ & \multicolumn{2}{|c|}{$3 \mathrm{mg} / \mathrm{kg} \mathrm{q} 4 \mathrm{w}$} & $\begin{array}{c}10 \mathrm{mg} / \mathrm{kg} \\
\mathrm{q} 8 \mathrm{w}\end{array}$ & $\begin{array}{c}10 \mathrm{mg} / \mathrm{kg} \\
\mathrm{q} 4 \mathrm{w}\end{array}$ & $3 \mathrm{mg} / \mathrm{kg}$ & $6 \mathrm{mg} / \mathrm{kg}$ \\
\hline \multirow[t]{2}{*}{$\begin{array}{l}\text { drug vs. placebo [n } \\
(\%)]\end{array}$} & Week 14 & \multicolumn{2}{|c|}{ 7/59 (11.9) } & $\begin{array}{l}13 / 58 \\
(22.4)\end{array}$ & 7 (8) vs. & \multicolumn{2}{|c|}{9 (11) vs. } & $\begin{array}{c}15 \text { (18) } \\
\text { vs. }\end{array}$ & $9(11)$ vs. & $\begin{array}{l}\text { (32.5) vs. } \\
(21.2)\end{array}$ & $\begin{array}{l}37.2 \mathrm{vs} \\
(21.2)\end{array}$ \\
\hline & Week 52 & \multicolumn{2}{|c|}{$58 / 112(51.8)$} & & $0(0) c$ & \multicolumn{2}{|c|}{$0(0) c$} & $0(0) c$ & $0(0) c$ & & \\
\hline \multicolumn{12}{|l|}{ 4. AEs and SAEs } \\
\hline \multirow{2}{*}{ Most frequently } & \multicolumn{4}{|c|}{ Placebo vs. drug No [\%] } & & Plac & o vs. drug & o [\%] & & $\begin{array}{r}\text { Placebo v } \\
{[\%}\end{array}$ & drug No \\
\hline & $6 \mathrm{mg}$ & & & & $3 \mathrm{mg} / \mathrm{l}$ & & $\begin{array}{c}3 \mathrm{mg} / \mathrm{kg} \\
\mathrm{q} 4 \mathrm{w}\end{array}$ & $\begin{array}{c}10 \mathrm{mg} / \mathrm{kg} \\
\mathrm{q} 8 \mathrm{w}\end{array}$ & $\begin{array}{c}10 \mathrm{mg} / \mathrm{kg} \\
\mathrm{q} 4 \mathrm{w}\end{array}$ & $3 \mathrm{mg} / \mathrm{kg}$ & $6 \mathrm{mg} / \mathrm{kg}$ \\
\hline General disorders & & & & & & & & & & & \\
\hline $\begin{array}{l}\text { injection-site } \\
\text { reaction }\end{array}$ & 5 (8.3) vs. & $(17.5)$ & $5(8.3)$ & $1(35.0)$ & & & & & & & \\
\hline Rash & & & & & $4(5 \%) v$ & $(6 \%)$ & $\begin{array}{c}4(5 \%) \\
\text { vs. } 7 \\
(8 \%)\end{array}$ & $\begin{array}{l}4(5 \%) \\
\text { vs. } 14 \\
(16 \%)\end{array}$ & $\begin{array}{l}4(5 \%) \\
\text { vs. } 11 \\
(14 \%)\end{array}$ & & \\
\hline Pain & & & & & $4(5 \%) \mathrm{v}$ & $(4 \%)$ & $\begin{array}{l}4(5 \%) \\
\text { vs. } 3 \\
(3 \%)\end{array}$ & $\begin{array}{l}4(5 \%) \\
\text { vs. } 7 \\
(8 \%)\end{array}$ & $\begin{array}{c}4(5 \%) \\
\text { vs. } 8 \\
(10 \%)\end{array}$ & & \\
\hline Nervous system & & & & & & & & & & & \\
\hline Headache & & & & & $\begin{array}{r}9(10 \% \\
\quad 25\end{array}$ & 22 & $\begin{array}{c}9(10 \%) \\
\text { vs. } 17 \\
(20 \%)\end{array}$ & $\begin{array}{c}9(10 \%) \\
\text { vs. } 21 \\
(24 \%)\end{array}$ & $\begin{array}{c}9(10 \%) \\
\text { vs. } 16 \\
(20 \%)\end{array}$ & $\begin{array}{c}31(11) \\
\text { vs. } 43 \\
(12)\end{array}$ & $\begin{array}{c}31(11) \\
\text { vs. } 42 \\
(11)\end{array}$ \\
\hline
\end{tabular}




\begin{tabular}{|c|c|c|c|c|c|c|c|c|}
\hline Any infection & & & $\begin{array}{c}34 \text { (40\%) vs. } 47 \\
(53 \%)\end{array}$ & $\begin{array}{c}34 \\
(40 \%) \\
\text { vs. } 40 \\
(47 \%) \\
\end{array}$ & $\begin{array}{c}34 \\
(40 \%) \\
\text { vs. } 56 \\
(64 \%) \\
\end{array}$ & $\begin{array}{c}34 \\
(40 \%) \\
\text { vs. } 58 \\
(73 \%) \\
\end{array}$ & & \\
\hline Serious Infection & 2 (3.3) vs. 1 (1.8) & 2 (3.3) vs. 5 (8.3) & $5(6 \%)$ vs. $1(1 \%)$ & $\begin{array}{l}5(6 \%) \\
\text { vs. } 5 \\
(6 \%) \\
\end{array}$ & $\begin{array}{l}5(6 \%) \\
\text { vs. } 5 \\
(6 \%) \\
\end{array}$ & $\begin{array}{c}5(6 \%) \\
\text { vs. } 3 \\
(4 \%) \\
\end{array}$ & & \\
\hline $\begin{array}{l}\text { Upper respiratory } \\
\text { tract infection }\end{array}$ & & & $\begin{array}{c}14 \text { (16\%) vs. } 29 \\
(33 \%)\end{array}$ & $\begin{array}{c}14 \\
(16 \%) \\
\text { vs. } 17 \\
(20 \%)\end{array}$ & $\begin{array}{c}14 \\
(16 \%) \\
\text { vs. } 21 \\
(24 \%)\end{array}$ & $\begin{array}{c}14 \\
(16 \%) \\
\text { vs. } 18 \\
(23 \%)\end{array}$ & $\begin{array}{l}60(21) \\
\text { vs. } 94 \\
(25)\end{array}$ & $\begin{array}{l}60(21) \\
\text { vs. } 106 \\
(28)\end{array}$ \\
\hline cough & & & $3(3 \%)$ vs. $8(9 \%)$ & $\begin{array}{l}3(3 \%) \\
\text { vs. } 6 \\
(7 \%)\end{array}$ & $\begin{array}{c}3(3 \%) \\
\text { vs. } 11 \\
(13 \%)\end{array}$ & $\begin{array}{l}3(3 \%) \\
\text { vs. } 12 \\
(15 \%)\end{array}$ & & \\
\hline $\begin{array}{c}\text { Nasopharyngitis / } \\
\text { Rhinitis }\end{array}$ & & & 4 (5\%) vs. 5 (6\%) & $\begin{array}{l}4(5 \%) \\
\text { vs. } 4 \\
(5 \%) \\
\end{array}$ & $\begin{array}{l}4(5 \%) \\
\text { vs. } 6 \\
(7 \%) \\
\end{array}$ & $\begin{array}{l}4(5 \%) \\
\text { vs. } 6 \\
(8 \%) \\
\end{array}$ & $\begin{array}{c}17(6) \text { vs. } \\
33(9)\end{array}$ & $\begin{array}{l}17 \text { (6) vs. } \\
40 \text { (11) }\end{array}$ \\
\hline \multicolumn{9}{|l|}{$\begin{array}{l}\text { Gastrointestinal } \\
\text { disorders (total) }\end{array}$} \\
\hline \multicolumn{9}{|l|}{ vomiting } \\
\hline Diarrhoea & & & $10(12 \%)$ vs. $7(8 \%)$ & $\begin{array}{c}10 \\
(12 \%) \\
\text { vs. } 8 \\
(9 \%) \\
\end{array}$ & $\begin{array}{c}10 \\
(12 \%) \\
\text { vs. } 7 \\
(8 \%) \\
\end{array}$ & $\begin{array}{c}10 \\
(12 \%) \\
\text { vs. } 10 \\
(13 \%) \\
\end{array}$ & & \\
\hline Abdominal pain & & & 7 (8\%) vs. $4(4 \%)$ & $\begin{array}{c}7(8 \%) \\
\text { vs. } 8 \\
(9 \%) \\
\end{array}$ & $\begin{array}{c}7(8 \%) \\
\text { vs. } 7 \\
(8 \%) \\
\end{array}$ & $\begin{array}{l}7(8 \%) \\
\text { vs. } 6 \\
(8 \%) \\
\end{array}$ & & \\
\hline $\begin{array}{l}\text { Additional info } \\
\text { available in study }\end{array}$ & \multicolumn{2}{|c|}{ Anti-ds DNA, Antibodies } & \multicolumn{4}{|c|}{ Death, } & & \\
\hline \multicolumn{9}{|l|}{$\begin{array}{l}\text { Comments: } \\
\text { a data estimated }\end{array}$} \\
\hline
\end{tabular}

Table 3b: Pharmacology data of clinical trials with infliximab in children and adults.

\begin{tabular}{|c|c|c|c|c|c|c|}
\hline & \multicolumn{2}{|c|}{$\begin{array}{l}\text { CHILDREN (JIA) ( } 4 \text { to } 17 \text { years of } \\
\text { age) }\end{array}$} & \multicolumn{4}{|c|}{ ADULTS (RA) } \\
\hline \multirow[b]{2}{*}{$\begin{array}{l}\text { Pharmacol- } \\
\text { ogy }\end{array}$} & \multicolumn{6}{|c|}{$\begin{array}{l}\text { - Neutralizes the biological activity of TNF } \alpha \text { by binding with high affinity to the soluble and transmembrane forms of TNF } \alpha \text { and inhibits binding of TNF } \alpha \text { with } \\
\text { its receptors (it does not neutralize TNF } \beta \text { (lymphotoxin- } \alpha \text { )). }\end{array}$} \\
\hline & \multicolumn{6}{|c|}{$\begin{array}{l}\text { - Biological activities attributed to TNF } \alpha \text { include: induction of pro-inflammatory cytokines such as interleukins (IL) } 1 \text { and } 6 \text {, enhancement of leukocyte } \\
\text { migration by increasing endothelial layer permeability and expression of adhesion molecules by endothelial cells and leukocytes, activation of neutrophil } \\
\text { and eosinophil functional activity, induction of acute phase reactants and other liver proteins, as well as tissue degrading enzymes produced by synoviocytes } \\
\text { and/or chondrocytes. }\end{array}$} \\
\hline \multirow[t]{2}{*}{ PD } & \multicolumn{6}{|c|}{$\begin{array}{l}\text { - In RA, treatment with REMICADE reduced infiltration of inflammatory cells into inflamed areas of the joint as well as expression of molecules mediating } \\
\text { cellular adhesion [E-selectin, intercellular adhesion molecule-1 (ICAM-1) and vascular cell adhesion molecule-1 (VCAM-1)], chemoattraction [IL-8 and } \\
\text { monocyte chemotactic protein (MCP-1)] and tissue degradation [matrix metalloproteinase (MMP) } 1 \text { and 3]. }\end{array}$} \\
\hline & \multicolumn{6}{|c|}{$\begin{array}{l}\text { - After treatment, patients exhibited decreased levels of serum IL-6 and C-reactive protein (CRP) compared to baseline. Peripheral blood lymphocytes } \\
\text { showed no significant decrease in number or in proliferative responses. }\end{array}$} \\
\hline $\begin{array}{c}\text { Data } \\
\text { Source }\end{array}$ & Ruperto 2007 & $\begin{array}{l}\text { Ruper- } \\
\text { to } 2009\end{array}$ & St.Clair 2004 & Ternant 2013 & Maini 1999 & Mori 2006 \\
\hline $\begin{array}{l}\text { Hematolog- } \\
\text { ic Events }\end{array}$ & $\begin{array}{l}\text { A higher proportion of } \\
\text { patients in the infliximab } \\
\text { groups }(1.7 \% \text { and } 8.8 \% \\
\text { in the } 3 \mathrm{mg} / \mathrm{kg} \text { and } 6 \mathrm{mg} / \\
\text { kg groups, respectively) } \\
\text { as compared with } \\
\text { placebo }(0 \%) \text { had at } \\
\text { least } 1 \text { decrease in the } \\
\text { absolute neutrophil count } \\
(<1.5 \times 103 \text { cells } / \mu \mathrm{L} \text { and } \\
\text { decrease } \geq 33 \%) .\end{array}$ & & & $\begin{array}{c}\text { Systemic } \\
\text { clearance } \\
\text { increased with } \\
\text { pre-infusion } \\
\text { C-reactive } \\
\text { protein } \\
\text { concentration } \\
\text { by } 20 \% \text {, } \\
\text { varying from } 3 \\
\text { to } 14 \mathrm{mg} / \mathrm{l} \text {, and } \\
\text { was decreased } \\
\text { by } 30 \% \text { when } \\
\text { MTX was co- } \\
\text { administered. }\end{array}$ & & \\
\hline
\end{tabular}


Overall, 25\% (26 of 102) of the patients with evaluable samples had antibodies to infliximab, with a higher incidence in the $3 \mathrm{mg} / \mathrm{kg}$ group (20 of 53 [38\%]) compared with the $6 \mathrm{mg} /$ kg group (6 of 49 [12\%]). In addition, the antibody among patients in the 3 $\mathrm{mg} / \mathrm{kg}$ group, with 8 of 20 patients $(40 \%)$ having a titer of 1:320 or higher (3 patients had titers of $1: 20,480)$, compared with only 2 of 6 patients (33\%) in the $6 \mathrm{mg} / \mathrm{kg}$ group. The safety profile for infliximab $3 \mathrm{mg} / \mathrm{kg}$ appeared to be less favourable in comparison with the 6-mg/kg dose. titers were notably higher

\begin{tabular}{|c|c|c|c|c|c|c|c|}
\hline \multirow[t]{4}{*}{$\begin{array}{c}\text { During } \\
\text { the } \\
\text { OLE, } \\
26 / 71 \\
(37 \%) \\
\text { pa- } \\
\text { tients } \\
\text { were } \\
\text { posi- } \\
\text { tive for } \\
\text { anti- } \\
\text { bodies } \\
\text { to } \\
\text { inflix- } \\
\text { imab, }\end{array}$} & & ANAs & $\begin{array}{c}\text { anti- } \\
\text { dsDNA }\end{array}$ & $\begin{array}{l}\text { Anti- in- } \\
\text { fliximab }\end{array}$ & $\begin{array}{c}\text { Antibodies } \\
\text { toward } \\
\text { infliximab were } \\
\text { detected in the } \\
\text { pre-infusion } \\
\text { serum of } \\
\text { three patients; } \\
\text { two of these } \\
\text { three patients } \\
\text { were also } \\
\text { treated with } \\
\text { methotrexate } \\
\text { and one was } \\
\text { not. Of note, } \\
\text { the infliximab } \\
\text { concentrations } \\
\text { for these three } \\
\text { patients were } \\
\text { below the limit } \\
\text { of detection } \\
\text { within } 4 \text { weeks } \\
\text { after }\end{array}$ & $\begin{array}{c}\text { Human } \\
\text { antichimeric } \\
\text { antibody (HACA) } \\
\text { formation could } \\
\text { not be measured } \\
\text { in most patients } \\
\text { receiving } \\
\text { infliximab } \\
\text { because serum } \\
\text { infliximab } \\
\text { interferes } \\
\text { with the assay. } \\
\text { However, of } \\
27 \text { infliximab- } \\
\text { treated patients } \\
\text { who stopped } \\
\text { treatment before } \\
30 \text { weeks, } 3 \\
\text { tested positive } \\
\text { for HACA ( } 2 \\
\text { with a titre of } \\
1 / 10 \text { and } 1 \text { with } \\
\text { a titre of } 1 / 40 \text { ). }\end{array}$ & $\begin{array}{l}\text { It is reported that } \\
\text { HACA formation may } \\
\text { possibly alter the } \\
\text { pharmacokinetics of } \\
\text { infliximab; however, } \\
\text { HACA was not detected } \\
\text { in patients with } \\
\text { rapid clearance when } \\
\text { their lowest serum } \\
\text { concentrations of } \\
\text { infliximab were below a } \\
\text { detectable limit of assays. }\end{array}$ \\
\hline & $6 \mathrm{mg} / \mathrm{kg}$ & $\begin{array}{c}34.3 \% \\
\text { patients }\end{array}$ & $\begin{array}{c}20.7 \% \\
\text { patients }\end{array}$ & $\begin{array}{c}6.7 \% \\
\text { patients }\end{array}$ & $\begin{array}{c}\text { infliximab } \\
\text { administration }\end{array}$ & & \\
\hline & placebo & $\begin{array}{c}11.3 \% \\
\text { patients }\end{array}$ & $\begin{array}{c}0.4 \% \\
\text { patients }\end{array}$ & & & & \\
\hline & \multicolumn{5}{|c|}{$\begin{array}{l}\text { One patient in the } 6 \mathrm{mg} / \mathrm{kg} \text { group developed a skin rash and ANA } \\
\text { positivity, but tested negative for serum anti-dsDNA antibodies; this } \\
\text { event was classified by the investigator as drug-induced lupus. }\end{array}$} & & \\
\hline
\end{tabular}

$\mathrm{PK}$
Phase III, international,

\begin{tabular}{|c|c|}
\hline Ruperto 2007 & PI \\
& \\
& \\
Phase III, & Pharma- \\
cokinetic \\
results \\
for single \\
doses of 3 \\
mg/kg to \\
10 mg/kg \\
in rheuma- \\
toid \\
\\
\\
\\
\\
\end{tabular}

\begin{tabular}{|c|c|c|}
\hline St.Clair, 2004 & Ternant 2013 \\
\hline $\begin{array}{c}\text { Multiple blood samples } \\
\text { were obtained from } \\
\text { each of 428 subjects } \\
\text { with active RA } \\
\text { who were enrolled } \\
\text { in a multicenter }\end{array}$ & Eighty-four \\
\hline
\end{tabular}

patients treated randomized, double-blind, placebo-controlled trial (ATTRACT). Pharmacokinetic modeling was used to predict the serum concentrations of infliximab after simulated infusions using doses and dosing intervals not evaluated in the trial. with infliximab for RA were included in a prospective noncomparative study. They were analysed between two consecutive infliximab infusions.
International double-blind placebo-controlled phase III clinical trial, 428 patients who had active RA were randomized to placebo, $3 \mathrm{mg} / \mathrm{kg}$ every 4 or 8 weeks or $10 \mathrm{mg} / \mathrm{kg}$ every 4 or 8 weeks. Patients were assessed every 4 weeks for 30 weeks.
Clinical pharmacokinetics (PK) of infliximab, using timeserum concentration profiles obtained from 21 RA patients who had received infliximab therapy in combination with methotrexate through 14 weeks. Patients receive an intravenous infusion of infliximab (3 mg/ $\mathrm{kg}$ or $200 \mathrm{mg}$ ) at weeks 0,2 , and 6 ,followed by maintenance therapy every 8 weeks. 


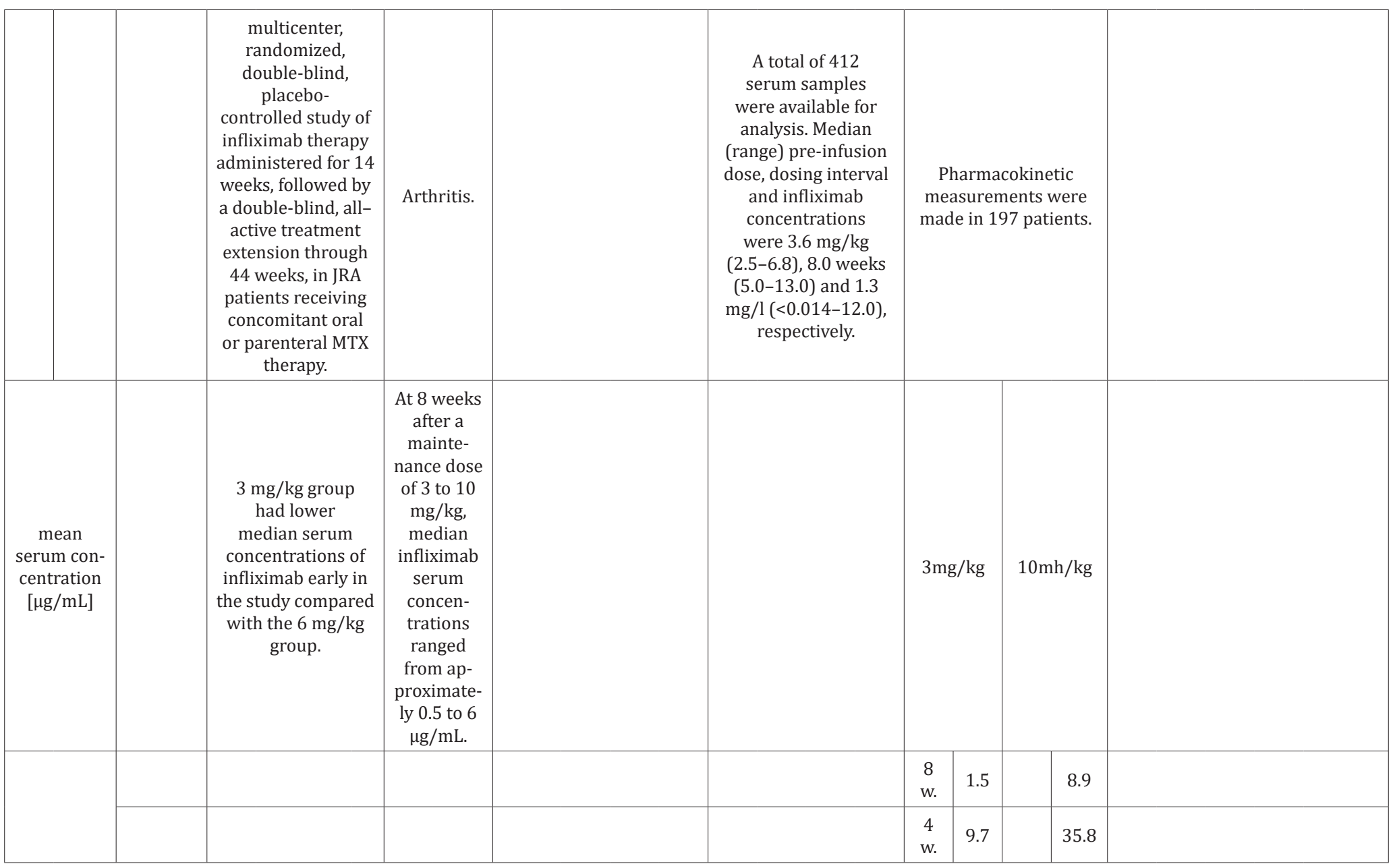




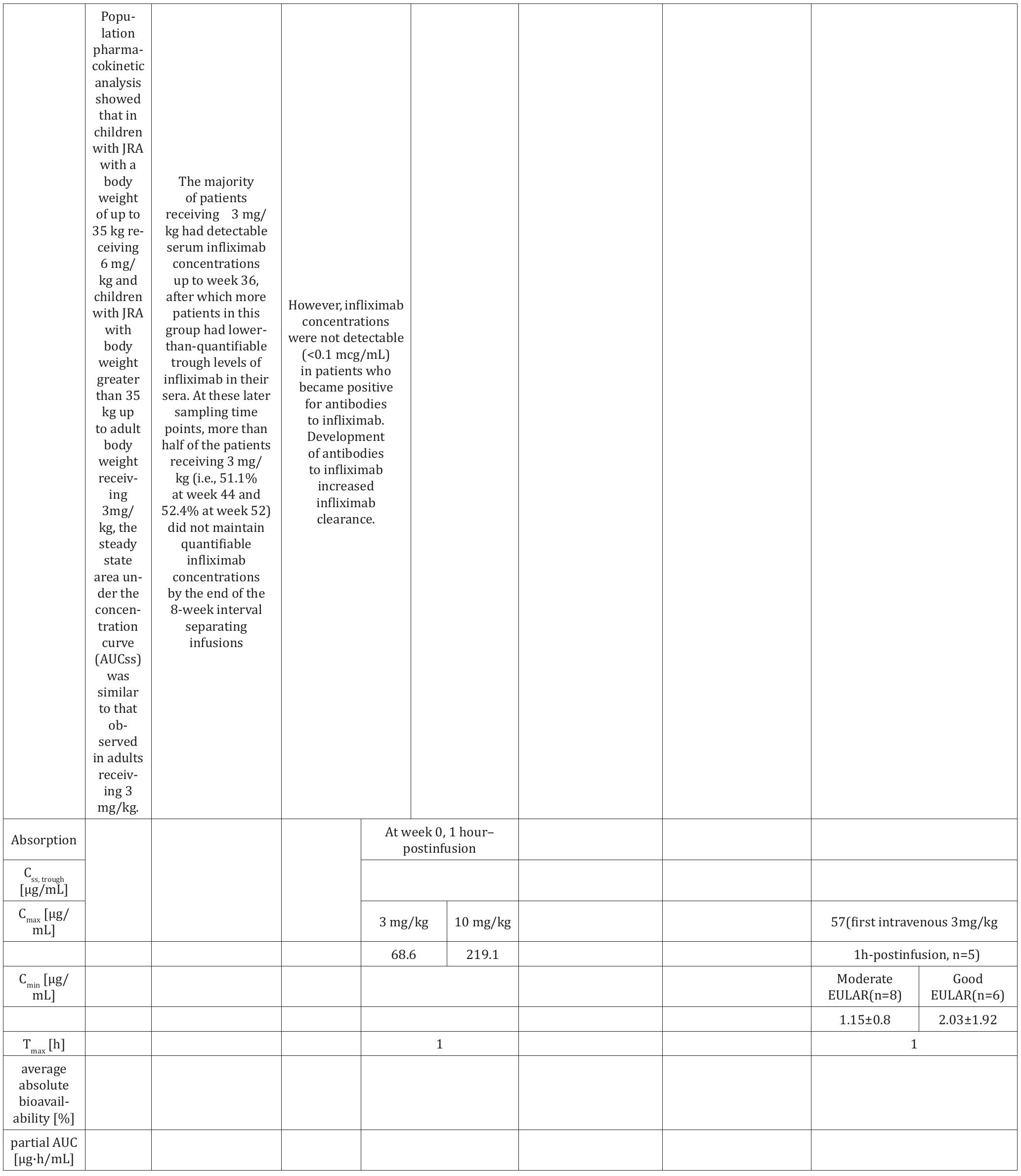




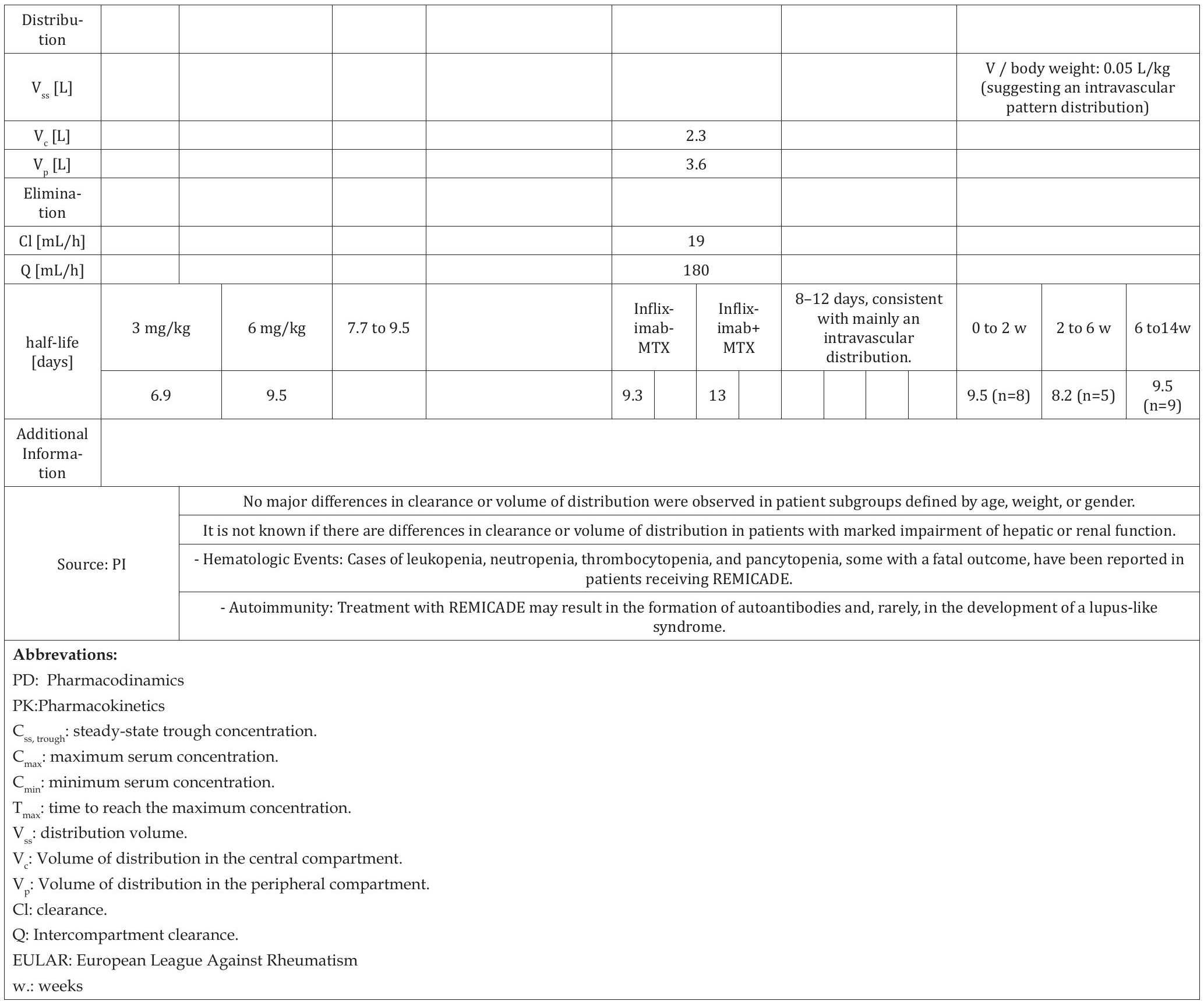

Table 4: Meta-Analysis: Results on ACR50 and ACR70 for etanercept showed a treatment effect for etanercept.

\begin{tabular}{|c|c|c|c|c|c|c|c|c|}
\hline Type III Tests of Fixed Effects & \multicolumn{4}{|c|}{ ACR 50} & \multicolumn{4}{c|}{ ACR 70 } \\
\hline Effect & Num $\boldsymbol{D F}$ & Den $\boldsymbol{D F}$ & $\boldsymbol{F}$ Value & P value & Num DF & Den DF & F Value & P value \\
\hline Treatment & 5 & 7 & 12.23 & 0.0024 & 5 & 7 & 23.65 & 0.0003 \\
\hline Age group & 1 & 7 & 0.19 & 0.6743 & 1 & 7 & 0.00 & 0.9688 \\
\hline Time in weeks & 1 & 7 & 1.32 & 0.2878 & 1 & 7 & 0.02 & 0.8917 \\
\hline
\end{tabular}


Table 5: Meta-analysis: Results on ACR50 and ACR70 for Adalimumab. Comparative data for adalimumab studies in children and adults confirmed a treatment effect in both groups.

\begin{tabular}{|c|c|c|c|c|c|c|c|c|}
\hline Type III Tests of Fixed Effects & \multicolumn{4}{|c|}{ ACR 50} & \multicolumn{4}{c|}{ ACR 70 } \\
\hline Effect & Num $\boldsymbol{D F}$ & Den $\boldsymbol{D F}$ & $\boldsymbol{F}$ Value & P value & Num DF & Den DF & F Value & P value \\
\hline Treatment & 11 & 24 & 60.12 & $<.0001$ & 11 & 24 & 33.60 & $<.0001$ \\
\hline Age group & 1 & 24 & 0.89 & 0.3542 & 1 & 24 & 3.01 & 0.0958 \\
\hline Time in weeks & 1 & 24 & 1.51 & 0.2314 & 1 & 24 & 3.28 & 0.0825 \\
\hline
\end{tabular}

However, there is no statistically significant treatment difference effect in the between-age or study-duration group for the endpoints ACR 50 and ACR 70.

Table 6: Meta-Analysis: Results on ACR50 and ACR70 for infliximab. Meta analysis of study data on infliximab shows no statistically significant treatment effect between adults and children.

\begin{tabular}{|c|c|c|c|c|c|c|c|c|}
\hline Type III Tests of Fixed Effects & \multicolumn{4}{|c|}{ ACR 50 } & \multicolumn{4}{c|}{ ACR 70 } \\
\hline Effect & Num DF & Den DF & F Value & P value & Num DF & Den DF & F Value & P value \\
\hline Treatment & 6 & 1 & 0.95 & 0.6559 & 6 & 1 & 1.56 & 0.5462 \\
\hline Age group & 1 & 1 & 12.13 & 0.1780 & 1 & 1 & 8.07 & 0.2155 \\
\hline Time in weeks & 1 & 1 & 3.08 & 0.3299 & 1 & 1 & 7.74 & 0.2197 \\
\hline
\end{tabular}

We do not present forest plots for infliximab due to numerically instable results.

\section{Etanercept}

A single pediatric clinical trial (JIA-I [17]) in 2000 was identified from the drug prescribing information (Table 1a). This trial involved a total of 120 patients; 51 were part of a double-blind, placebo-controlled study with a nearly 1:1 ratio (26:25), and 69 participated in an open-label trial with etanercept only. A total of four studies in RA in adults, two in 1999 (Study I [18] and II [19]), one in 2000 (Study III [20, 21]) and one in 2004 (Study IV [22, 23]) were identified. Two compared etanercept with placebo, and two compared etanercept with methotrexate.

\section{Dosage and Study Duration}

Children were dosed for three to four months with $0.4 \mathrm{mg} /$ $\mathrm{kg}$ bw etanercept, and a maximum of $25 \mathrm{mg}$ per dose. Across all studies, adults received 10 or $25 \mathrm{mg}$ etanercept over a period of six or twelve months. Only two trials $[17,24]$ included a placebo in the control arm and etanercept only in the study drug arm. All other trials in adults were performed in combination with methotrexate in experimental and placebo groups (Table 1a).

\section{ACR Response}

Assessment of the ACR study data differed between children and adults. The pediatric studies used the ACR30, ACR50 and ACR70 criteria and the adult studies the ACR20, ACR50 and ACR70 criteria. Thus, only the data for ACR50 and ACR70 could be considered for direct comparison (Table 1a and Figure 1). In addition, the selected time schedule for ACR assessment differed greatly between studies. While ACR50 and ACR70 were evaluated in week 12 or 16 in children, these were evaluated in week 4,24 or week 48 in adults. Only Study II and Study IV showed an assessment in week 12. The respective numbers had to be estimated from figures in the publication. In the JIA study of Lovell et al., $64 \%$ of the 69 patients met the definition of $50 \%$ improvement, and $36 \%$ the definition of $70 \%$ improvement at the end of the study [17]. There was a similar rate in the Moreland et al., study (59\% of the $25 \mathrm{mg}$ group achieved an ACR20 response and 40\% achieved an ACR50 response) at 24 weeks [24].

The response rate achieved with etanercept treatment in combination with methotrexate varied between $39-59 \%$ for ACR50 at $25 \mathrm{mg}$ and $15-36 \%$ for ACR70 at 24 weeks in all other three studies in adults. Meta-analysis showed a treatment effect for etanercept in both, adults and children. However, no effect of age or study duration on the treatment effect could be measured (Table 4 and Figure 1). Thus, the results obtained on drug efficacy and dose showed no difference in adults and children. 


\section{A) ACR50}

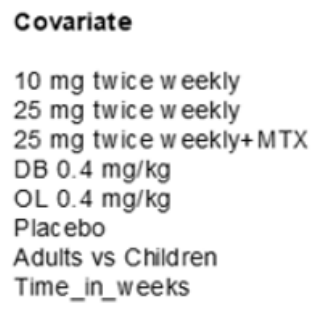

Time in weeks

A) ACR70

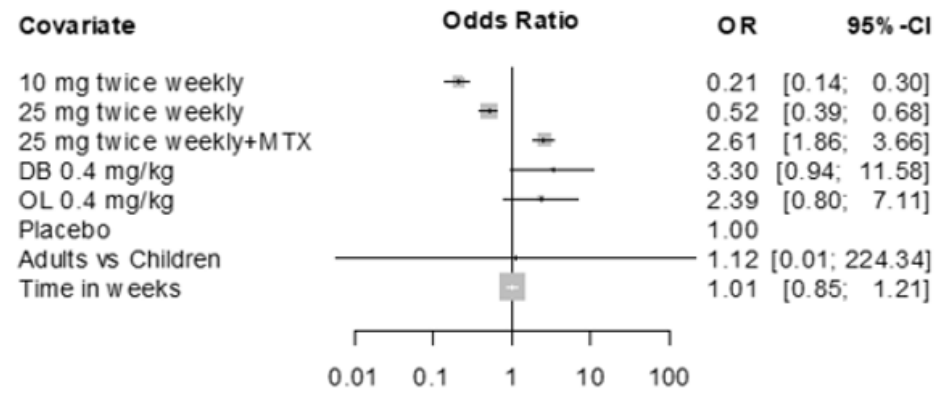

Figure 1: Forest plot results on ACR50 (A) and ACR70 (B) ETANERCEPT as graphical representation of the meta-analysis here includes five studies [17-20].

The first column shows names of the covariates in the model. Odds ratios for dose levels are reported with placebo as the reference. Results are shown together with $95 \%$ confidence interval. The black dot on each line shows you the odds ratio for each variable.

\section{Meta-Analysis Results of ACR50 AND ACR70}

Results of mixed-effects logistic regression for adults and children concerning treatment effects, age group (adults vs children) and study duration (time in weeks) can be viewed in the following tables. numDF, degrees of freedom of term; denDF, degrees of freedom of error term; F, variance ratio; P, error probability; critical value of significance: $\mathrm{p}<0.05$.

\section{Adverse Events}

Most frequent adverse events (AEs) in both children and adults were injection site reaction, upper respiratory tract infection, headache, rhinitis, nausea and rash. The drug demonstrated a favorable risk-benefit profile in children and adults. No lifethreatening events were observed (Table $1 \mathrm{a}$ ).

\section{Pharmacokinetics}

The population pharmacokinetic analysis by Yim et al. confirmed that $0.8 \mathrm{mg} / \mathrm{kg}$ once weekly and $0.4 \mathrm{mg} / \mathrm{kg}$ twice-weekly subcutaneous regimens of etanercept had equivalent clinical outcomes. This served as a basis for the recent FDA approval of the $0.8 \mathrm{mg} / \mathrm{kg}$ once-weekly regimen in pediatric patients with JRA [25] (Table 1b).

\section{Adalimumab}

Two pediatric clinical trials, PJIA-I [26] and PJIA-II [27], were identified in the prescribing information. These were carried out in 2008 and 2014 and involved a total of 336 patients; 133 as part of a double-blind, placebo-controlled study (75 received methotrexate as supplemental therapy, 58 did not) and 203 in an open-label trial with adalimumab with or without methotrexate (112 and 91, respectively) (Table 2a). In comparison, five pivotal studies in adults, two in 2003 (RA-I [28] and RA-IV [29]), two in 2004 (RA-II [30] and RA-III [31]) and one in 2006 (RA-V [32]) were identified. Two compared adalimumab to placebo, and two were placebocontrolled plus methotrexate. One study compared adalimumab to methotrexate only, as well as to adalimumab plus methotrexate.

\section{Dosage and Study Duration}

The studies in children were carried out over 12 to 30 months with $24 \mathrm{mg} / \mathrm{m}^{2}$ adalimumab, and a maximum of 20 or $40 \mathrm{mg}$ per dose. Adults received 20, 40 or $80 \mathrm{mg}$ over a period of six, six and a half or 13-24 months. The drug was given subcutaneously in all cases. The PI allows 10, 20 or $40 \mathrm{mg}$ for children, depending on the body weight, and $40 \mathrm{mg}$ is the approved dosage for adults as described in PI (Table 2a). 


\section{ACR response}

Assessment of ACRs included were ACR30, ACR50, ACR70 and ACR90 for children, and ACR20, ACR50 and ACR70 for adults. Children were evaluated in week 12, 16, 24, 48, 60 and/or 96, and adults in week 24, 26, 52 and/or week 104. Thus, only ACR50 and ACR70 at 24 weeks are comparable (Table 2a and Figure 2). PJIA-II and RA-I, RA-III and RA-IV assessed ACR50 and ACR70 in week 24. However, these studies are not well comparable as their design differs considerably. PJIA-II was a placebo-controlled study, while RA-II and RA-III tested placebo plus methotrexate. RA-IV was also placebo-controlled, but allowed DMARDs during the study, whereas PJIA-II did not. Only studies with adalimumab in combination with methotrexate at week 24 were eligible for ACR50 and ACR70 comparative analyses. In the pediatric study PJIA-II, $83 \%$ of patients achieved ACR50, and in the adult RA-I study, $22 \%$ reached ACR50 at week 24 with 20 mg maximum dose treatment. In the PJIA-I study, ACR50 was achieved in $64 \%$ of the children at the 40 mg maximum dose compared with $37 \%$ in the RA-I study, $86 \%$ in the RA-III study and $59 \%$ in the RA-V study, respectively. $73 \%$ of children achieved ACR70 in the PJIA-II study, whereas only $7 \%$ and $9 \%$ of adult patients using $20 \mathrm{mg}$ at 24 weeks were comparable as demonstrated in the RA-I and RA-II studies, respectively. At a $40 \mathrm{mg}$ dose of adalimumab the response varied between $46 \%$ and $71 \%$ at weeks 16-48 in the PJIA-I study compared with 37\%, 23\%, 86\% and $59 \%$ with the combination of adalimumab and methotrexate in adults in RA-I, RA-II, RA-III and RA-V studies, respectively.

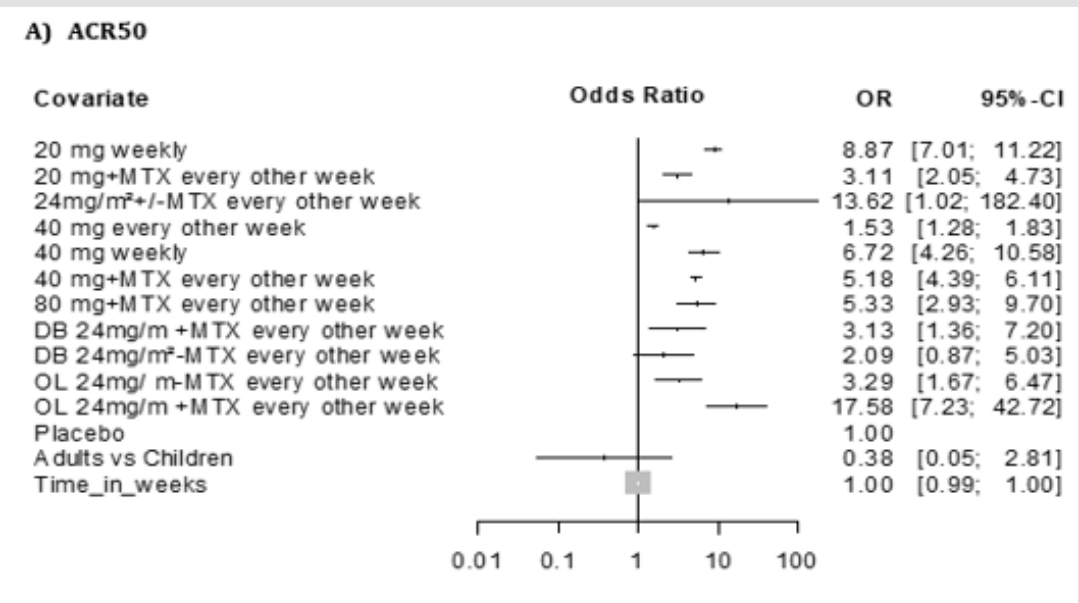

B) ACR70

Covariate

$20 \mathrm{mg}$ weeky

$20 \mathrm{mg}+\mathrm{MTX}$ every other week

$24 \mathrm{mg} / \mathrm{m}^{2}+/-$ MTX every other week

$40 \mathrm{mg}$ every other week

$40 \mathrm{mg}$ every othe

$40 \mathrm{mg}+\mathrm{MTX}$ every other week

$80 \mathrm{mg}+$ MTX every other week

DB $24 \mathrm{mg} / \mathrm{m}+$ MTX every other week

DB $24 \mathrm{mg} / \mathrm{m}^{2}$-MTX every other week

OL $24 \mathrm{mg} / \mathrm{m}-\mathrm{MTX}$ every other week

OL $24 \mathrm{mg} / \mathrm{m}+\mathrm{MTX}$ every other week

Place bo

Adult vs Children

Children

Time in weeks

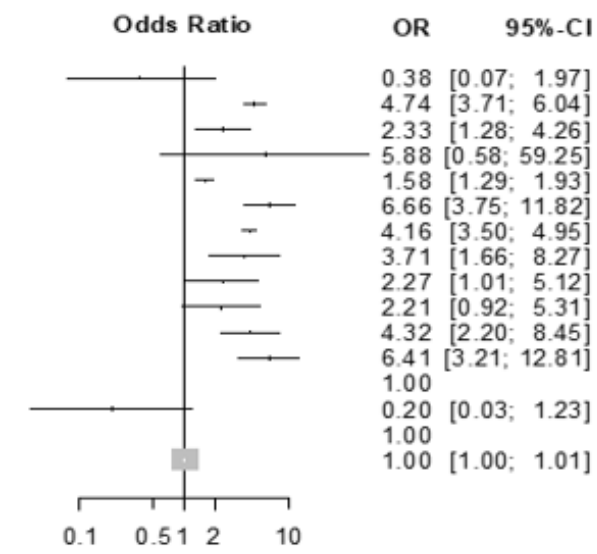

Figure 2: Forest plot results on ACR50 (A) and ACR70 (B) ADALIMUMAB, includes seven studies in the meta-analysis [25-31]. The first column shows names of the covariates in the model.

Odds ratios for dose levels are reported with placebo as the reference. Results are shown together with $95 \%$ confidence interval. Odds ratios for dose levels are reported with placebo as the reference. Results are shown together with $95 \%$ confidence interval.

Meta analysis of ACR50/70 revealed that comparative data for adalimumab studies in children and adults confirmed a treatment effect in both groups. However, there is no statistically significant treatment difference effect in the study duration for the endpoints
ACR 50 and ACR 70 (Table 5 and Figure 2). Similar to etanercept, results obtained on adalimulab on efficacy and dose showed no difference in adult and children. 


\section{Adverse Events}

The most common event was injection site reactions. The most common AEs leading to discontinuation of adalimumab treatment were clinical flare reaction, rash and pneumonia. The rate of serious infections was 4.6 per 100 patients (Table $2 a$ ).

\section{Pharmacokinetics}

A higher apparent clearance of adalimumab in the presence of Neutralizing anti-adalimumab antibody (AAA) and lower clearance with increasing age in patients aged 40 to $>75$ years was observed in population pharmacokinetic analyses in patients with RA. No gender-related pharmacokinetic differences were observed after correction for a patient's body weight. Healthy volunteers and patients with rheumatoid arthritis displayed similar adalimumab pharmacokinetics. $\mathrm{C}_{\text {max }}, \mathrm{T}_{\text {max }}$, bioavailability and elimination values are only available for adults as described in the PI (Table 2b).

\section{Golimumab}

Golimumab has been confirmed to be an effective treatment for patients with RA in phase III clinical trials as evaluated by traditional measures of disease activity. The efficacy and safety profile of golimumab appears to be similar to other anti-TNF agents. However, golimumab has the potential advantage of once monthly subcutaneous administration and the possibility of both subcutaneous and intravenous administration. A study of CNTO 148 (golimumab) in children with juvenile idiopathic arthritis (GO-KIDS trial) to evaluate the efficacy and safety of golimumab is ongoing. This study enrolls patients who have active JIA and at least five joints with active arthritis that have poor response to methotrexate. The GO-KIDS trial consists of three parts and aims to assess the efficacy and safety of golimumab in pediatric patients aged 2 to $<18$ years with active JIA with a polyarticular course (at least five joints) despite therapy with methotrexate (10 to 30 $\mathrm{mg} / \mathrm{m}^{2} /$ week) for at least 6 months [33]. The trial involved 173 patients (87.9\% white, $75.7 \%$ female; median age 12 years, age 2 to 17 years) with moderately active disease. Nineteen $(11 \%)$ patients discontinued in part 1 of the trial due to lack of efficacy $(n=14)$, adverse effects ( $n=4)$, and withdrawal of consent $(n=1)$.

\section{Dosage and Study Duration}

The drug (the usual adult dose for RA of an initial dose of 50 mg subcutaneously once a month or $2 \mathrm{mg}$ per $\mathrm{kg}$ iv infusion over 30 minutes at weeks 0 and 4, then every 8 weeks thereafter. It should be given in combination with methotrexate. Corticosteroids, nonbiologic DMARDs, analgesics and/or NSAIDs may be continued during treatment with this drug [33].

\section{ACR Response}

During the first phase of the trial, 151 of the remaining 173 $(87.3 \%)$ patients achieved a $30 \%$ improvement from baseline in 3 of the 6 assessed criteria (active joint count, limitation of motion joint count, physician global assessment, patient/parent global assessment, Childhood Health Assessment Questionnaire, and acute-phase reactant level) without worsening of the remaining criteria, and $36.1 \%$ of patients displayed inactive disease status. The investigators randomized 154 patients to part 2 of the trial. The primary endpoint was not met; at week 48 the flare rates were comparable in those receiving placebo and golimumab $(52.6 \%$ vs. $59.0 \%$; $\mathrm{P}=0.41$ ). The major secondary endpoints were also comparable between the placebo and treatment groups. The rates of inactive disease/clinical remission in patients receiving placebo + methotrexate or golimumab + methotrexate, for example, were $27.6 \% / 11.8 \%$ and $39.7 \% / 12.8 \%$, respectively. Children with JIA in at least five joints displayed a rapid response to golimumab during the open-label, part 1 portion of the trial. During this portion of the trial, $36 \%$ of patients displayed inactive disease following the golimumab injection schedule. The sustained improvement in JIR was maintained in the placebo and treatment groups compared with baseline.

\section{Adverse Events}

Through week 48, adverse events, serious adverse events, and serious infections were reported in $87.9 \%, 13.3 \%$, and $2.9 \%$ of all randomized patients, respectively. The most frequent serious adverse event was exacerbation of JIR. Death, active tuberculosis, or malignancy did not occur. Golimumab missed the primary endpoint in JIA. The reasons for the similarity in flare rates between the arms is unclear, and further study is needed if the regimen ultimately proves worthy of clinical use [33]. No Meta analysis for Golimumab on adult and pediatric data could be performed, as the data from the study in JIA is not publically available.

\section{Infliximab}

Study Description: A multicenter randomized doubleblind placebo-controlled trial of infliximab in 117 children with polyarticular JIA did not find a statistically significant effect of infliximab $3 \mathrm{mg} / \mathrm{kg}$ intravenous infusion therapy plus methotrexate on ACR-Pedi responses as compared with placebo at 14 weeks [34]. The open-label extension (OLE, 52-204 weeks) of the study involved 78 patients. However, $34 \%$ discontinued infliximab prematurely, mostly by withdrawing consent due to lack of efficacy [35]. Overall, $30 \%$ of the children continued the study up to week 204 (Table 3a). The two pivotal studies in RA in adults were performed in 1999 (Study RA I, ATTRACT, [36]) and 2004 (Study RA II, ASPIRE, [37]). Both trials were placebo-controlled and allowed methotrexate. They worked with 3, 6 or $10 \mathrm{mg} / \mathrm{kg}$ i.v. application of infliximab.

ACR Response: After 14 weeks, following crossover from placebo to infliximab $6 \mathrm{mg} / \mathrm{kg}$, ACR50 and ACR70 responses at week 52 were achieved in $70 \%$ and $52 \%$ of the children. However, 
there was no statistically significant difference between the placebo group and the treatment group. Meta analysis supports that study data on infliximab shows no statistically significant treatment effect in children compared to adults. Also, the impact of age and study duration did not play a significant role (Table 6).

Adverse Events: The pediatric trial demonstrated that infliximab was safe, though the $3 \mathrm{mg} / \mathrm{kg}$ group had a less favorable safety profile, with a higher incidence of injection-site reactions and more serious infections. As the efficacy of infliximab in a pivotal study has not revealed a superior effect compared with placebo [34], the FDA did not approve infliximab for JIA, although it is still used in children. It is recommended as backup drug to treat JIA in the guidelines for JIA treatment [38] at the usual pediatric dose for JIA: 10 years or older: $3 \mathrm{mg} / \mathrm{kg}$ via iv infusion at weeks 0,2 , and 6 , followed by infusions every 8 weeks [39]. Moreover, infliximab is approved for the therapy of refractory Crohn's disease in children over 6 years (Table 3a).

Pharmacokinetics: The childrens' trial observed formation of antibodies to infliximab, antinuclear antibody or anti-dsDNA antibodies in greater proportion in the $3 \mathrm{mg} / \mathrm{kg}$ group [34,35]. This confirmed results from one adult study [37], although other studies could not detect anti-chimeric antibodies, or only below detection limit $[36,40,41]$ (Table 3b).

\section{Discussion}

The introduction of PIPs aimed to initiate a formal approval process for new medicinal products to avoid unauthorized use in children. In this review, the JIA indication in children, with RA as a counterpart in adults, and TNF- $\alpha$ blocking agents were selected as model diseases and drugs for comparison and evaluation of the data obtained from clinical studies in the new immunomodulatory drug space. TNF blocking agents are currently the only drug group with a number of compounds authorized in children and adults to treat JIA and in adults in RA, thus providing most experience in this drug class. Studies with etanercept in children showed the utility of TNF- $\alpha$ blocking agents in JIA for the first time. The PI for etanercept allows a dose of $0.8 \mathrm{mg} / \mathrm{kg}$ for children $<63 \mathrm{~kg}$ and up to $50 \mathrm{mg}$ for children $\geq 63 \mathrm{~kg}$. $50 \mathrm{mg}$ is also the approved dose for adults. The detailed PK parameters to support the dose selection in either population could not be identified and were addressed in only a few studies. A direct comparison of ACR response between children and adults was only partially possible as the time points for assessments differed considerably between both groups. Thus, it is unclear how the dose for children was selected. However, as the dose is set at a similar level for adults and children, these studies supported the idea that the dose for children could potentially have been extrapolated from the adult studies. Furthermore, no new safety issues or efficacy data were identified in proof-of-concept trials with children. Thus, the pediatric study results did not lead to any significant differences in dosage or safety profile compared with those in adults but confirmed the efficacy in JIA. Meta-analysis showed no difference on the treatment effect for etanercept in adults and children.

Similar findings were true for the comparison of dosage between adult and children for adalimumab. The PI shows a dose of 10, 20 or $40 \mathrm{mg}$ for children, depending on the body weight; $40 \mathrm{mg}$ is the approved dosage for adults. Thus, the pediatric study results did not lead to any significant differences in dosage that could not have been predicted from the adult studies. ACR response data was also only partially directly comparable due to difference in assessment values and schedules. In addition, no new safety and efficacy data was obtained by these studies. However, no statistically significant treatment difference effect in the beween-age or study-duration group for the endpoints ACR 50 and ACR 70 (Table 5) could be observed. Golimumab was used in trials described above in JIA or RA. So far, no new safety and efficacy aspects have been identified in the JIA study, but the primary endpoint was not met in children. Adverse effects with anti-TNF- $\alpha$ blockers are generally mild e.g. local skin reactions/infusion reactions, and are mostly transient. Minor infections e.g. upper respiratory tract infections are common. The risk of developing tuberculosis seems higher with the monoclonal antibody's infliximab and adalimumab, compared with etanercept $[42,43]$. Autoimmune phenomena such as drug-induced lupus, demyelinating disease, uveitis, psoriasis and inflammatory bowel disease were rather rare.

The risk of malignancies was reported to be increased in children. The post-marketing surveillance data on antiTNF- $\alpha$ agents collected by the FDA reported 48 malignancies developing in children, of which 20 occurred in children with rheumatic conditions [44]. However, $88 \%$ of these children were also receiving other immunosuppressive drugs, including corticosteroids, azathioprine and methotrexate. Approximately $50 \%$ of the malignancies reported were lymphomas, leukemia and melanoma. The FDA and EMA added a boxed warning with regard to the possible increased risk of malignancy, especially lymphomas, in children treated with anti-TNF- $\alpha$ agents. Despite this, a recent summary of worldwide pediatric malignancies in children treated with etanercept did not find an overall increased risk. However, the authors acknowledged that it is difficult to assess the actual risk due to the rarity of malignant events, the underlying higher risk of lymphomas and leukemias in children with JIA and the confounding use of other immunosuppressants [45].

The time before the marketing approval of drugs is particularly important, as the overall aim of drug development in clinical trials should focus on patient benefit to make sure that access of drugs to patients is as simple and fast as possible. However, the studies performed to support marketing approvals in children does not seem to support this overall aim, as shown in the model based on 
TNF- $\alpha$ blocking agents. Therefore, prolonging the drug approvals process does not benefit children, and promotes off-label pediatric used as these drugs are already marketed for use in adults. All four TNF- $\alpha$ blocking agents discussed here are approved in adults for RA, and all have been tested in children for JIA. The results broadly confirm the findings in adult studies other than infliximab, which has not been approved at a dose of $3 \mathrm{mg} / \mathrm{kg}$ for JIA (although it is continued to be used in children). Based on the similarity of dose administered in adults and children, the assumption is that the key parameters are likely to be similar across age groups for a range of biologics. Therefore, the question arises - is it important to carry out confirmatory studies in children? Are these studies really necessary or can the data for biologics be extrapolated if the expression of the respective target is the same in adults and children? The data reviewed suggests that the results obtained in adult RA studies are likely to be useful in predicting the dose, efficacy and safety for children with JIA. It therefore does not support further performance of extensive proof-of-concept studies in children.

\section{Conclusions}

The overall aim of drug development in clinical trials should focus on patient benefit, making sure that patient access to drugs is as simple and fast as possible. However, the studies performed to support marketing approvals in children do not seem to support this overall aim, and actually prolong the approvals process. They also promote off-label paediatric use as the drugs are already marketed for use in adults. All four of the TNF- $\alpha$ blocking agents discussed here are approved in adults for RA, and all have been tested in children in JIA. Based on the similarity of dose administered in adults and children for the two biologics approved in children, the assumption is that the key parameters are likely to be similar across age groups for a range of biologics. Therefore, the question arises - is it important to carry out confirmatory studies in children? Are large pivotal studies really necessary or can the data for biologics be extrapolated if the expression of the respective target is the same in adults and children? Our review of the data suggests that the results obtained in adult RA studies are likely to be useful in predicting the dose, efficacy and safety for children with JIA. It therefore does not support further performance of extensive proof-of-concept studies in children in specific targeted indications and based on mode of actions of a medicinal product.

However, infliximab and golimumab missed the primary endpoint for efficacy in JIA. The failure of these two drugs suggests that the differences in PK/PD parameters might play an important role in children's immune responses to biologic drugs, especially those expressed as chimeric or pegylated proteins. This differing immune response may have a bigger role in children than in adults, with higher levels of immunogenicity and neutralizing antibodies reducing the efficacy of the drugs. It is interesting to note that there were no studies identified in the public domain that looked at these drugs in terms of target expression in lymphocytes, or PK/ PD studies in children. The data reviewed suggests that the results obtained in adult RA studies are likely to be useful in predicting the dose, efficacy and safety for children with JIA for certain products, however, the results from the two unapproved drugs might indicate that expression studies of the target and PK/PD studies are important to translate adult studies successfully in children. The need for further extensive efficacy and safety studies in children is therefore challenged. PK/PD studies plus modelling and simulation based on adult dose may be needed in children to help in finding optimal dose for children and to confirm a PD effect. In certain situations, for example in drugs of the same class, an extrapolation approach could avoid unnecessary further studies in the pediatric population.

\section{Acknowledgment}

We are very thankful to Dr. Richard Vesely (EMA, Rheumatology Division) for review of the manuscript and most valuable comments.

\section{Declarations}

a) None of the authors received any financial support or other benefits from commercial sources for the work reported on in the manuscript, or any other financial interests which could create a potential conflict of interest or the appearance of a conflict of interest with regard to the work.

b) Any of the authors consent to participate. Regarding the fact of a systematic review, ethics approval was not relevant.

c) All data which were discussed are given in the literature list.

d) None of the authors has competing interests

e) This article is a systematic review; therefore, no funding was necessary.

f) Authors' contributions: all authors interpretated and discussed the data and prepared the manuscript.

g) Acknowledgements are not to be listed.

\section{References}

1. GaBI (2015) Biosimilars of etanercept 201420 March.

2. GaBI (2014) Biosimilars of adalimumab. 20 February 2015.

3. EMA (2011) Assessment Report for Simponi (golimumab) Procedure No.

4. Pfizer (2015) Author's comment: Searching for 'Enbrel' at uprovides a download of the prescribing information and a link to additional information for health care professionals (this requires a login as a Pfizer employee or via DocCheck. 
5. Abbott (2012) Author's comment: A search for Humira (adalimumab) on Abbot's website, brings up nine documents, including the 2012 Annual Report, the privacy policy and Abbott's Twitter feed, but no information about clinical trials.

6. https://www.novartis.com/

7. Roche (2015) Author's comment: Actemra (tocilizumab) leads to press releases that contain basic information about the drug and the pivotal studies.

8. https://www.actemra.com/

9. https://www.humira.com/

10. Ilaris. Author's comment: Ilaris (canakinumab) has its own website for downloading the full prescribing information. The site for health care professionals depicts important safety information for the medication but does not reveal information on clinical studies.

11. EMA. Author's comment: The European Medicines Agency (EMA) website allows searching for therapeutics and the respective European public assessment reports (EPAR). Every medicine granted a central marketing authorization by the European Commission is based on an assessment of the EMA's Committee for Medicinal Products for Human Use (CHMP). The page can be browsed for the medicine alphabetically, either under its trade name or under the generic name, for example Humira or adalimumab. The record includes approval status, indication, authorization details, product information and assessment history. EPAR summaries can be downloaded, and PIPs are also available.

12. European Union Clinical Trials Register. Author's comment: The European Union Clinical Trials Register lists all interventional clinical trials that are conducted inside the EU and the European Economic Area (EEA) as well as trials outside the EU/EEA that are linked to European paediatric drug development. At the day of access (4 February 2015) 24,783 clinical trials with a EudraCT protocol were registered, out of which 3375 were clinical trials conducted with subjects less than 18 years old. Another 10,296 older paediatric trials are stored that were conducted before the Paediatric Regulation in 2007 and in scope with the Art.45 of the Paediatric Regulation until 2006.

13. ClinicalTrials.gov. Author's comment: A registry and results database of publicly and privately supported clinical studies conducted worldwide. The website is based in the USA. It listed 183,742 studies with locations in all 50 US states and in 187 countries at the last access (7 February 2015). It is possible to search on the name of the drug. Advanced search includes the specific disease condition, titles, age group, study ID, and outcome measures, among others.

14. CenterWatch. Author's comment: CenterWatch is a US-based website and was the first to publish detailed information about active clinical trials that could be accessed by patients and their advocates. There is an option in 'Drug information' that allows searching for FDA-approved drugs. These can be viewed by year, company, conditions, therapeutic area or drug names. Drugs are listed by their trade names, not by their active substance, and include the company, the approval status and the treatment area. There is general information about the drug, a summary of the clinical results as to be found in the prescribing information, a list of the most common side effects, and a short explanation of the mechanism of action.

15. Google. Author's comment: The official clinical trial websites did not offer full access to key data on any of the clinical trials identified. The respective publications could be only be found by searching on www. google.com for the name of the drug, the disease condition, the study population or other information from the prescribing information.

16. Medline. Author's comment: The identified pivotal study was downloaded from Medline All pivotal studies were identified by and PubMed by name of the drug, disease condition, search term 'clinical trial' e.g. adalimumab, 'juvenile idiopathic arthritis' 'clinical trial'.
17. Lovell DJ, Giannini EH, Reiff A, Cawkwell GD, Silverman ED, et al. (2000) Etanercept in children with polyarticular juvenile rheumatoid arthritis. Pediatric Rheumatology Collaborative Study Group. N Engl J Med 342(11): 763-769.

18. Mathias SD, Colwell HH, Miller DP, Moreland LW, Buatti M, et al. (2000) Health-related quality of life and functional status of patients with rheumatoid arthritis randomly assigned to receive etanercept or placebo. Clin Ther 22(1): 128-139.

19. Weinblatt ME, Kremer JM, Bankhurst AD, Bulpitt KJ, Fleischmann RM, et al. (1999) A trial of etanercept, a recombinant tumor necrosis factor receptor:Fc fusion protein, in patients with rheumatoid arthritis receiving methotrexate. $\mathrm{N}$ Engl J Med 340(4): 253-259.

20. Bathon JM, Martin RW, Fleischmann RM, Tesser JR, Schiff MH, et al. (2000) A comparison of etanercept and methotrexate in patients with early rheumatoid arthritis. N Engl J Med 343(22): 1586-1593.

21. Genovese MC, Bathon JM, Martin RW, Fleischmann RM, Tesser JR, et al. (2002) Etanercept versus methotrexate in patients with early rheumatoid arthritis: two-year radiographic and clinical outcomes. Arthritis Rheum. 46(6): 1443-1450.

22. Klareskog L, van der Heijde D, de Jager JP, Gough A, Kalden J, et al. (2004) Therapeutic effect of the combination of etanercept and methotrexate compared with each treatment alone in patients with rheumatoid arthritis: double-blind randomised controlled trial. Lancet 363(9410): 675-681.

23. Van der Heijde D, Klareskog L, Singh A, Tornero J, Melo-Gomes J, et al. (2006) Patient reported outcomes in a trial of combination therapy with etanercept and methotrexate for rheumatoid arthritis: the TEMPO trial. Ann Rheum Dis 65(3): 328-334.

24. Moreland LW, Schiff MH, Baumgartner SW, Tindall EA, Fleischmann RM, et al. (1999) Etanercept therapy in rheumatoid arthritis. A randomized, controlled trial. Ann Intern Med. 130(6): 478-486.

25. Yim DS, Zhou H, Buckwalter M, Nestorov I, Peck CC, et al. (2005) Population pharmacokinetic analysis and simulation of the timeconcentration profile of etanercept in pediatric patients with juvenile rheumatoid arthritis. J Clin Pharmacol 45(3): 246-256.

26. Kingsbury DJ, Bader-Meunier B, Patel G, Arora V, Kalabic J, et al. (2014) Safety, effectiveness, and pharmacokinetics of adalimumab in children with polyarticular juvenile idiopathic arthritis aged 2 to 4 years. Clin Rheumatol 33(10): 1433-1441.

27. Lovell DJ, Ruperto N, Goodman S, Reiff A, Jung L, et al. (2008) Adalimumab with or without methotrexate in juvenile rheumatoid arthritis. N Engl J Med 359(8): 810-820.

28. Weinblatt ME, Keystone EC, Furst DE, Moreland LW, Weisman MH, et al. (2003) Adalimumab, a fully human anti-tumor necrosis factor alpha monoclonal antibody, for the treatment of rheumatoid arthritis in patients taking concomitant methotrexate: the ARMADA trial. Arthritis Rheum 48(1): 35-45.

29. Furst DE, Schiff MH, Fleischmann RM, Strand V, Birbara CA, et al. (2003) Adalimumab, a fully human anti-tumor necrosis factor-alpha monoclonal antibody, and concomitant standard antirheumatic therapy for the treatment of rheumatoid arthritis: results of STAR (Safety Trial of Adalimumab in Rheumatoid Arthritis). J Rheumatol 30(12): 2563-2571.

30. Van de Putte L, Atkins C, Malaise M, Sany J, Russell AS, et al. (2004) Efficacy and safety of adalimumab as monotherapy in patients with rheumatoid arthritis for whom previous disease modifying antirheumatic drug treatment has failed. Ann Rheum Dis 63(5): 508-516.

31. Keystone EC, Kavanaugh AF, Sharp JT, Tannenbaum H, Hua Y, et al. (2004) Radiographic, clinical, and functional outcomes of treatment with adalimumab (a human anti-tumor necrosis factor monoclonal antibody) 
in patients with active rheumatoid arthritis receiving concomitant methotrexate therapy: a randomized, placebo-controlled, 52-week trial. Arthritis Rheum 50(5): 1400-1411.

32. Breedveld FC, Weisman MH, Kavanaugh AF, Cohen SB, Pavelka K, et al. (2006) The PREMIER study: A multicenter, randomized, double-blind clinical trial of combination therapy with adalimumab plus methotrexate versus methotrexate alone or adalimumab alone in patients with early, aggressive rheumatoid arthritis who had not had previous methotrexate treatment. Arthritis \& Rheumatism 54(1): 26-37.

33. Brunner HI, Ruperto N, Tzaribachev N, Horneff G, Wouters C, et al (2014) A Multi-Center, Double-Blind, Randomized-Withdrawal Trial of Subcutaneous Golimumab in Pediatric Patients with Active Polyarticular Course Juvenile Idiopathic Arthritis Despite Methotrexate Therapy: Week 48 Results: Abstract 933. 2014 Annual Scientific Meeting of the American College of Rheumatology/Association of Rheumatology Health Professionals (ACR/ARHP; 201416 November; Boston, 2014.

34. Ruperto N, Lovell DJ, Cuttica R, Wilkinson N, Woo P, et al. (2007) A randomized, placebo-controlled trial of infliximab plus methotrexate for the treatment of polyarticular-course juvenile rheumatoid arthritis. Arthritis Rheum 56(9): 3096-3106.

35. Ruperto N, Lovell DJ, Cuttica R, Woo P, Meiorin S, et al. (2010) Long-term efficacy and safety of infliximab plus methotrexate for the treatment of polyarticular-course juvenile rheumatoid arthritis: findings from an open-label treatment extension. Ann Rheum Dis 69(4): 718-722.

36. Maini R, St Clair EW, Breedveld F, Furst D, Kalden J, et al. (1999) Infliximab (chimeric anti-tumour necrosis factor alpha monoclonal antibody) versus placebo in rheumatoid arthritis patients receiving concomitant methotrexate: a randomised phase III trial. ATTRACT Study Group. Lancet 354(9194): 1932-1939.

37. St Clair EW, van der Heijde DM, Smolen JS, Maini RN, Bathon JM, et al. (2004) Combination of infliximab and methotrexate therapy for early rheumatoid arthritis: a randomized, controlled trial. Arthritis Rheum 50(11): 3432-3443.

ISSN: 2574-1241

DOI: $10.26717 / B J S T R .2021 .39 .006244$

Jürgen Brunner. Biomed J Sci \& Tech Res (C) (P) This work is licensed under Creative

Submission Link: https://biomedres.us/submit-manuscript.php
38. Oommen PT, Huppertz H-I (2013) Handlungsempfehlung nach der Leitlinie Therapie der Juvenilen idiopathischen Arthritis. Monatsschrift Kinderheilkunde 161(1): 60-62.

39. (2015) Drugs.com. Infliximab Dosage.

40. Mori S A (2007) relationship between pharmacokinetics (PK) and the efficacy of infliximab for patients with rheumatoid arthritis: characterization of infliximab-resistant cases and PK-based modified therapy. Mod Rheumatol 17(2): 83-91.

41. Ternant D, Ducourau E, Perdriger A, Corondan A, Le Goff B, et al. (2014) Relationship between inflammation and infliximab pharmacokinetics in rheumatoid arthritis. Br J Clin Pharmacol 78(1): 118-128.

42. Dixon WG, Hyrich KL, Watson KD, Lunt M, Galloway J, et al. (2010) Drugspecific risk of tuberculosis in patients with rheumatoid arthritis treated with anti-TNF therapy: results from the British Society for Rheumatology Biologics Register (BSRBR). Ann Rheum Dis 69(3): 522-528.

43. Tubach F, Salmon D, Ravaud P, Allanore Y, Goupille P, et al. (2009) Risk of tuberculosis is higher with anti-tumor necrosis factor monoclonal antibody therapy than with soluble tumor necrosis factor receptor therapy: The three-year prospective French Research Axed on Tolerance of Biotherapies registry. Arthritis Rheum 60(7): 1884-1894.

44. Diak P, Siegel J, La Grenade L, Choi L, Lemery S, et al. (2010) Tumor necrosis factor alpha blockers and malignancy in children: forty-eight cases reported to the Food and Drug Administration. Arthritis Rheum 62(8): 2517-2524.

45. McCroskery P, Wallace CA, Lovell DJ, Stryker S, Chernyukhin N, et al. (2010) Summary of worldwide pediatric malignancies reported after exposure to etanercept. Pediatr Rheumatol Online J 8: 18.

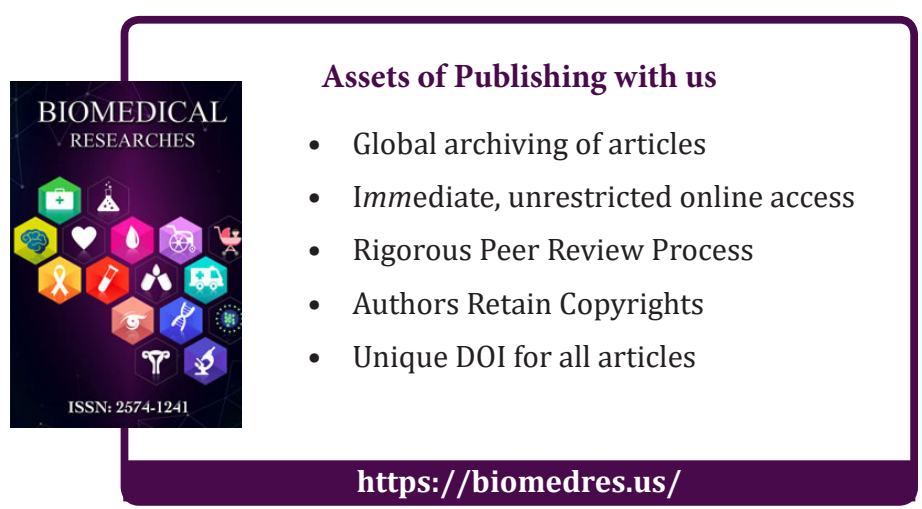

